\title{
REVIEW ARTICLE \\ A review of risk factors for bovine tuberculosis infection in cattle in the UK and Ireland
}

\author{
J. M. BROUGHAN ${ }^{1 *}$, J. JUDGE ${ }^{2}$, E. ELY ${ }^{1}$, R. J. DELAHAY ${ }^{2}$, G. WILSON ${ }^{2}$, \\ R. S. CLIFTON-HADLEY ${ }^{1}$, A. V. GOODCHILD ${ }^{1}$, H. BISHOP ${ }^{1}$, J. E. PARRY ${ }^{1}$ \\ AND S. H. DOWNS ${ }^{1}$ \\ ${ }^{1}$ Animal and Plant Health Agency - Weybridge, New Haw, Addlestone, Surrey, UK \\ ${ }^{2}$ National Wildlife Management Centre, Animal and Plant Health Agency, Woodchester Park, Nympsfield, \\ Gloucestershire, UK
}

Received 23 March 2016; Final revision 21 May 2016; Accepted 1 June 2016; first published online 25 July 2016

\section{SUMMARY}

Bovine tuberculosis (bTB) is an important disease of cattle caused by infection with Mycobacterium bovis, a pathogen that may be extremely difficult to eradicate in the presence of a true wildlife reservoir. Our objective was to identify and review relevant literature and provide a succinct summary of current knowledge of risk factors for transmission of infection of cattle. Search strings were developed to identify publications from electronic databases to February 2015. Abstracts of 4255 papers identified were reviewed by three reviewers to determine whether the entire article was likely to contain relevant information. Risk factors could be broadly grouped as follows: animal (including nutrition and genetics), herd (including bTB and testing history), environment, wildlife and social factors. Many risk factors are inter-related and study designs often do not enable differentiation between cause and consequence of infection. Despite differences in study design and location, some risk factors are consistently identified, e.g. herd size, bTB history, presence of infected wildlife, whereas the evidence for others is less consistent and coherent, e.g. nutrition, local cattle movements. We have identified knowledge gaps where further research may result in an improved understanding of bTB transmission dynamics. The application of targeted, multifactorial disease control regimens that address a range of risk factors simultaneously is likely to be a key to effective, evidence-informed control strategies.

Key words: Bovine tuberculosis, cattle, Mycobacterium bovis, risk factor, transmission, wildlife.

\section{INTRODUCTION}

Bovine tuberculosis (bTB) caused by Mycobacterium bovis infection is an important infection of cattle and can also infect a wide range of domestic and wild animals as well as humans [1]. Cattle act as the

\footnotetext{
* Author for correspondence: Dr J. M. Broughan, Department of Epidemiological Sciences, Animal \& Plant Health Agency, Woodham Lane, New Haw, Addlestone, Surrey KT15 3NB, UK. (Email: jenny.broughan@gmail.com)
}

maintenance hosts in many countries and the infection has proved extremely difficult to eradicate in domestic species once it has become established in a wildlife reservoir [2]. The incidence and epidemiology of bTB varies widely both internationally and locally [3-5]. Much of Europe is officially bTB free but the infection is endemic in cattle in parts of England, Wales, Ireland and Spain and other parts of Europe, which are dissimilar in terms of environmental features and wildlife reservoirs [6, 7]. Transmission of $M$. bovis is influenced by many factors including the intrinsic 
characteristics of the bacterium and potential host, the persistence of the bacterium in different environments, the probability of exposure of infected animals, e.g. cattle or wildlife vectors and/or fomites and the effectiveness of control strategies such as removal of infected animals.

Assessment of risk is dependent on unbiased measurement of factors associated with transmission between the bacterium and host and accurate classification of the infection status of animals and herds. A risk factor is defined as a characteristic, that in its presence increases the likelihood of the detection of infection, and they may be causal or non-causal [8]. Many risk factors are inter-related, e.g. each animal production system has its own distribution of sexes, breeds and age groups, which contribute to the exposure profile of each herd. Diagnostic tests for bTB range from those used in live cattle [e.g. tuberculin skin test (TST) and blood tests for interferon-gamma (IFN- $\gamma$ ) or antibodies] to post-mortem inspection confirmed with culture for $M$. bovis. Intrinsic test performance varies with the animal's immunological profile, disease infection stage and many other factors. For example, increasing the frequency of skin tests, a feature of intensified surveillance and control strategies for bTB, can modulate cell-mediated immunity and depress the response to subsequent skin tests $[9,10]$.

The relative importance of different risk factors for M. bovis transmission will vary with the background prevalence and magnitude of other risks. An understanding of risks and how they may interact is therefore necessary to understanding the epidemiology of the disease and the design of bTB eradication and control policies and forms the focus of this review.

\section{METHODS AND RESULTS}

A series of search strings were developed to identify relevant papers from CAB Abstracts, Web of Science, Medline and Current Contents electronic databases (see Supplementary material for the specific search strings). Two sets of searches were performed, the first deliberately excluding Mycobacterium avian paratuberculosis (MAP) and the second, specifically including it as a risk factor. The results of these were then combined. The search period was not limited historically and initially ended on 14 March 2013. Abstracts to 3738 non-duplicate references identified were reviewed by three reviewers to determine whether the entire article was likely to contain relevant information. Twenty-eight abstracts were reviewed by two reviewers to detect any perceived inconsistencies in selection. Inconsistencies were resolved through discussion, which then informed abstract selection. All publications that specifically investigated the risk of infection to cattle, or where that risk could be inferred, were included and the full text was requested. Papers in German, Spanish, Italian and French that were selected for further review were translated into English. Entire texts for selected papers were then obtained and assigned to one of ten full-text reviewers who each had a specific risk factor category as follows: animal-level, herd-level, environment and landscape features, herd history including previous testing, wildlife factors, and other risk factors. Reviewers were free to add further papers that had been omitted during the electronic search. The search was updated to 6 February 2015 using the original search criteria and a further 517 references identified, of which 81 were considered potentially relevant by one of the original reviewers.

The search was not limited geographically, but during the review emphasis was placed on references that could improve understanding of the Great Britain (GB) epidemiological situation. Methodology and reporting was consistent with PRISMA (http://www. prisma-statement.org) where possible with respect to the introduction, eligibility criteria, information sources, search and discussion, and as far as the qualitative assessment of the publication allowed.

\section{ANIMAL-LEVEL RISK FACTORS}

\section{Genetics}

Significant variation in heritability of susceptibility to bTB has been reported in studies of dairy cattle, mainly Holstein Friesian pure bred or crosses, in GB [11] and in Ireland [12]. In these population-based studies, around $16 \%$ and $18 \%$ of the variance in bTB resistance, measured by responsiveness to the single intradermal comparative cervical tuberculin (SICCT) test and postmortem evidence of infection, respectively, was estimated to be heritable [13]. There has been less investigation of heritability of resistance in beef herds. However, a study in Ireland has estimated heritability of susceptibility to bTB of around $13 \%$ in beef herds and also reported variation in susceptibility across different beef breeds [14]. These large studies, using surveillance data from thousands of cattle, may underestimate the contribution of heritability due to misclassification of the resistant phenotype because of 
imperfect accuracy of diagnostic tests and variation in level of exposure to M. bovis [15]. Greater variability in the estimates of heritability of susceptibility to bTB has been observed in high- compared to low-infection prevalence herds [14].

Resistance to bTB is likely to be multifactorial and polygenic [16]. In addition to heritability studies using phenotype data, candidate and whole genome approaches are being taken [15]. These approaches have indicated that resistance can be conferred by a single nucleotide polymorphism. Both breeding strategies and genomic selection are likely to have utility in bTB control [17-19]. Breeding for performance traits has led to large increases in milk outputs from dairy cows. Until recently the latter was accompanied with a reduction in fertility [20]. No association between susceptibility to M. bovis infection and economically important traits has been measured to date [21].

\section{Breed}

The earliest evidence for differences in resistance to bTB infection by breed originates from the 1920s and 1930s [15, 22]. Evidence mainly originates from Africa and strongly suggests that native cattle such as zebu, found in pastoral environments, are more resistant to bTB than introduced European cattle [22-26]. A weakness of some comparisons of bTB prevalence between breeds is the reliance on an antemortem test which may be less specific than evidence from post-mortem examination. There has been comparatively far less evaluation of the differences in the susceptibility to infection between European breeds. A study in India showed a threefold higher prevalence of SICCT test reactors in Jersey cattle compared to Holstein Friesian [27] but differences in exposure to M. bovis between breeds require exploration.

The UK Bovine HapMap Consortium has illustrated that greater diversity exists in allele frequencies between cattle breeds than within breeds [28]. Greater variability in resistance might be anticipated with beef cattle than with cattle in the modern dairy sector since the latter are more homogeneous in terms of breed.

\section{Sex}

Differences in bTB prevalence by sex are confounded by differences in the production environment and husbandry. Contact rates are higher for many dairy cattle. Additionally, milk-producing dairy cattle and suckler cows tend to have longer lives than beef cattle, increasing the lifetime probability of exposure to $M$. bovis [29, 30]. Incidence of bTB infection in dairy cattle, aged $\geqslant 2$ years, was $40 \%$ higher than beef cattle, although incidences in very young cattle ( $0-1$ years) were similar [31]. Most studies report a higher prevalence or incidence of bTB in female cattle compared to males [31-37], but not all [38], and none comprehensively controlled for differences in infection pressure, production environment and husbandry. At this time, an intrinsic difference in susceptibility to bTB between male and female cattle has not been demonstrated.

\section{Reproductive status and milk yield}

Few studies have examined the effect of reproductive status on susceptibility to bTB infection, possibly because of the difficulty in separating out gestation and lactation effects. The dairy cow experiences large hormonal shifts and stresses throughout production and it seems likely that these will affect both her response to diagnostic tests that measure immunological factors and susceptibility to infection. In contrast to susceptibility to bTB infection, cows in the weeks before and after calving tend to have weaker reactions to the TST, but the IFN- $\gamma$ is less affected [39]. Evidence is primarily found in studies outside of Europe and in the absence of stringent control programs where animals may experience advanced clinical disease. In Bangladesh, consumption of infected milk is also a potential (pseudo-vertical) transmission route for infection between cows and calves and a higher prevalence of bTB was observed in lactating cows compared to pregnant cows [40]. In Argentina, calves fed raw milk from a herd with endemic bTB were more likely to test positive (caudal fold test) than calves fed replacement milk substitute [41]. However, a large cohort study in Northern Ireland found no evidence of an increased risk of bTB in the progeny of TB-confirmed dams compared to those born to non-reactors in the same herd [risk ratio $1 \cdot 2$, 95\% confidence interval (CI) $0 \cdot 8-1 \cdot 79]$ [42].

\section{Age}

Virtually all studies reviewed reported that the prevalence of bTB infection increased with age $[23,27,34$, 43-48]. The relationship between bTB infection and age is generally shown as monotonic or linear although a U-shaped relationship has also been reported $[23,49]$. Modelling bTB surveillance data from GB 
showed that age-specific incidence increased monotonically to 24-36 months, followed by a levelling-off, with cattle aged between 12 and 36 months experiencing the highest rates of infection [31]. The most likely explanation for a positive correlation between bTB infection risk and longevity is a higher probability of contact and/or prolonged exposure to other infected cattle, wildlife or environmental contamination; infected cattle aged $>36$ months are possibly more responsive to the skin test [31] and therefore more likely to be detected in surveillance tests. A review of age effects in Tanzania, Zambia, Chad and Ireland also concluded that the positive association with increasing prevalence of bTB is a result of cumulative exposure [50]. Other possibilities include decline in resistance with age [1]. The influence of latency on detection and transmission of bTB in cattle is not known, although it is recognised as an important influence on disease prevalence and transmission in human infection with M. tuberculosis [51].

\section{Nutritional status and body condition}

Poor nutrition can suppress the cellular immunity response and increase susceptibility to infectious diseases [52-54]. Responsiveness to the SICCT test was positively correlated with body condition score and fat production in lactating Holstein-Friesian dairy cows in GB, which implies some association between susceptibility or at least responsiveness to the diagnostic test [21]. A cross-sectional study of cattle from herds with bTB infection found that significantly lower levels of the dietary selenium-requiring enzyme glutathione peroxidase were associated with a higher prevalence of post-mortem confirmed infection [55]. However, two Irish studies comparing animals with energy-restricted and unrestricted diets did not detect significant differences in bTB infection [56, 57]. Reports from Ethiopia are similarly mixed, with one study reporting a higher prevalence of bTB in animals with lower body condition scores [47] while another found no differences [44]. Future research needs to distinguish nutritional status/dietary factors and body condition from the immunological consequences of infection and the possible confounding effects of breed and other factors.

\section{Behavioural factors}

Contact networks between and within wild and domestic animals are heterogeneous [58, 59]. Cattle are inquisitive towards new objects and calves and some adult cattle are particularly so [60]. A study using proximity data loggers identified individual adult cattle with higher levels of contact both with other cattle in the herd and with badgers [61]. In a New Zealand study, $86 \%$ of the tuberculin test-positive cattle were among the most dominant fifth in the herd, and in four of five herds, the dominant animals investigated a sedated possum (the principal wildlife vector of bTB) most actively [62]. The differing contact behaviour of cattle towards live and inanimate objects implies that the individual risks of exposure to infection are heterogeneous.

\section{Concurrent infection}

Parasitic helminth infection status has been shown to be negatively correlated with bTB infection status in bovids [63-65]. Evidence suggests that infection with the helminth Fasciola hepatica may bias the immunological response towards a Th2 (eosinophilic) type at the expense of the Th1 (cell-mediated) immune response that influences the ability to control M. bovis [65]. Concurrent infection with or vaccination against MAP can influence the sensitivity and specificity of diagnostic tests for bTB $[66,67]$ (see below for further discussion). Outbreaks of bTB in two herds with a concurrent bovine viral diarrhoea (BVD) infection have been described anecdotally [68]. Compared to calves with $M$. bovis infection alone, calves co-infected with BVD and $M$. bovis show non-significantly increased bacterial shedding in nasal secretions, in experimental infections [69]. Further studies are needed, however, to evaluate whether there is an association between the two diseases.

\section{HERD-LEVEL RISK FACTORS}

Many factors describing the characteristics and management of herds have been associated with infection risk, but the direction of findings is inconsistent, even between studies conducted using a similar sampling frame [70, 71], possibly due to difficulty in characterising management factors accurately. A number of observational studies relating to herd-level risk factors within the UK and Ireland in specific circumstances have been well reviewed recently [72-75]. Rather than add to these, we have supplemented these with information from other countries that may inform the situation in GB. 


\section{Herd size}

Herd size is the most frequently identified risk factor for bTB incidents (herds that are found to have at least one infected animal). Dynamic modelling has shown that, adjusting for test performance, the increased probability of between-animal contacts in larger herds could increase within-herd transmission [76]. Most studies, but not all [77-79], conclude that the risk of infection detected in a herd increases with herd size; this holds true across a broad geographical and prevalence range (Table 1). Herd size may be a proxy for other factors, such as replacement policy, farm acreage, number of premises and neighbouring herds; each of which may be independently associated with the risk of a bTB incident. Additionally, most studies have not adjusted for the imperfect specificity of diagnostic tests for bTB which may affect the strength of association since the number of animals that are false positives will also increase with herd size. However, increased herd size could also result in increased risk of disease persistence.

\section{Herd type}

Dairy herds are generally considered to be more at risk of infection than beef herds because of longer life expectancy of the former and management practices that increase the risk of contact with other cattle [31, 50, 80]. Relatively few studies have considered herd type and of those, even fewer studies differentiate between beef fattening/finishing herds and beef breeding/suckler herds. The relative risk to beef cattle may be greater in areas where there is a local wildlife reservoir because beef cattle more frequently use rough or dispersed grazing. Direct contact between cattle and badgers at pasture is relatively rare [81], although indirect contact may be more common. In Italy, enterprises consisting of both dairy and beef animals, presented a greater risk [odds ratio (OR) 4.92, 95\% CI 1.26-19.19] than exclusively dairy enterprises, attributed to differences in purchasing policy [78]. Dairy herds experienced a recurrent bTB incident sooner than non-dairy herds in Northern Ireland, even after controlling for herd size [82], but a similar study in Ireland showed that dairy animals had a lower risk of a future restriction [83]. GB surveillance data indicate that the relationship between bTB incidence rate and herd type may be a result of the larger sizes of dairy herds and their location [84].

Dairy reactors to field tests for bTB appear to be less likely than non-dairy reactors to have post-mortem evidence of infection such as culture, histological evidence or macroscopic lesions typical of bTB PMC than non-dairy [55, 84-86]. In Northern Ireland the adjusted odds ratio for visible lesions in non-dairy reactors detected during routine surveillance was reported to be twice that in dairy [86]. The reason for the differences in post-mortem evidence of infection confirmation between dairy and beef production classes exposed to bTB is currently unknown [87].

\section{Total farm area, fragmentation and neighbouring herds}

Many authors identified the importance of contact between adjacent herds as a risk factor. This can be expressed in terms of lengths of common boundary, fragmentation of holdings, or observed contact with cattle from contiguous farms [70, 88, 89]. Farm size (acreage) has been associated with a higher probability of a bTB incident [90, 91], even after controlling for herd size [92] and it may be a proxy for increased risk of infection from contiguous premises or for increased wildlife contact. Operating over multiple premises has been associated with infection in GB [71, 90] although not in all studies [91, 93].

Many studies have shown an increased risk of bTB spread associated with bTB in neighbouring or contiguous herds. In Ireland, $23-25 \%$ of incidents were attributed to spread from herds on adjacent farms [94] and herds with a neighbouring infected herd were almost four times as likely to sustain a bTB incident themselves [95]. In Northern Ireland, $\sim 40 \%$ of breakdowns were attributed to the presence of a neighbouring herd with a breakdown [89]. Contact with an infected neighbouring cattle herd was associated with persistent incidents (lasting more than 5 years) in Spain [92] and was associated with a more than twofold increase in the odds of a bTB incident in high incidence areas of England and Wales [70]. In Ireland, it was estimated that being within $1 \mathrm{~km}$ of higher animal incidence in the previous 2 years accounted for $35 \%$ of bTB incidents [96]. However, distinguishing between spread from one herd to another and sharing a common source of infection is difficult where there is a significant reservoir of infection in wildlife.

\section{Cattle movements}

A large number of studies have considered the risk of introducing stock in general and in specific scenarios, 
Table 1. Risk factors identified in the literature according to theme, country in which the study was conducted and case definition

\begin{tabular}{|c|c|c|c|c|c|c|c|c|c|c|c|c|c|c|c|c|c|}
\hline Country & Diag. & \multicolumn{4}{|l|}{ Animal } & \multicolumn{7}{|l|}{ Herd } & \multicolumn{3}{|c|}{ Environment } & \multicolumn{2}{|l|}{ Wildlife } \\
\hline Ireland & SICCT & $\mathrm{x}$ & & & & & & & & & & & & & & & [11] \\
\hline Ireland & SICCT & $\mathrm{x}$ & & & & & & & & & & & & & & & [297] \\
\hline GB & SICCT & & & & & & $\mathrm{x}$ & & & & & & & & & & [283] \\
\hline GB & SICCT & & & & $\mathrm{x}$ & & & $\mathrm{x}$ & & & & & & & & & {$[31]$} \\
\hline GB & SICCT & & & & & & $\mathrm{x}$ & & & & & & & & & & [76] \\
\hline Italy & PMC & & & & & & & $\mathrm{x}$ & & $\mathrm{x}$ & & & & & & & {$[78]$} \\
\hline N. Ireland & Rct TB & & & & & & $\mathrm{x}$ & $\mathrm{x}$ & & $\mathrm{x}$ & & & $\mathrm{x}$ & & & & [82] \\
\hline Ireland & Rct TB & & & & & & $\mathrm{x}$ & $\mathrm{x}$ & & & & $\mathrm{x}$ & $\mathrm{x}$ & & & & [83] \\
\hline Spain & PMC & & & & $\mathrm{x}$ & & & $\mathrm{x}$ & & & & & & & & & [298] \\
\hline N. Ireland & PMC & & $\mathrm{x}$ & & $\mathrm{x}$ & & $\mathrm{x}$ & $\mathrm{x}$ & & & & & & & & & [86] \\
\hline Ireland & PMC & & & & $\mathrm{x}$ & & $\mathrm{x}$ & $\mathrm{x}$ & & & & & $\mathrm{x}$ & & & & {$[88]$} \\
\hline N. Ireland & PMC & & & & & & & & & & & & $\mathrm{x}$ & & & $\mathrm{x}$ & [89] \\
\hline England & PMC & & & & & $\mathrm{x}$ & $\mathrm{x}$ & & & & & & & & & & [90] \\
\hline England & SICCT + & & & & & $\mathrm{x}$ & & & $\mathrm{x}$ & $\mathrm{x}$ & & & & & & & [71] \\
\hline England & Pst TB & & & $\mathrm{x}$ & & & $\mathrm{x}$ & $\mathrm{x}$ & $\mathrm{x}$ & $\mathrm{x}$ & & & & $\mathrm{x}$ & & $\mathrm{x}$ & [93] \\
\hline England & SICCT + & & & & & & $\mathrm{x}$ & & $\mathrm{x}$ & $\mathrm{x}$ & & & & & & & [93] \\
\hline Scotland & SICCT + & & & & & & & & & $\mathrm{x}$ & & & & & & & [106] \\
\hline Belgium & PMC & & & & & & $\mathrm{x}$ & & & $\mathrm{x}$ & & & $\mathrm{x}$ & & $\mathrm{x}$ & & [103] \\
\hline England & PMC & & & & & & $\mathrm{x}$ & $\mathrm{x}$ & $\mathrm{x}$ & $\mathrm{x}$ & & & & & & & [6] \\
\hline England & PMC & & & $\mathrm{x}$ & & & & & $\mathrm{x}$ & & $\mathrm{x}$ & & & & & & [114] \\
\hline Spain & SICCT+ & & & $\mathrm{x}$ & & & & & & & $\mathrm{x}$ & & & $\mathrm{x}$ & & & [115] \\
\hline England & PMC & & & & & & $\mathrm{x}$ & & $\mathrm{x}$ & & & & & $\mathrm{x}$ & & & [116] \\
\hline Spain & SICCT+ & & & & & & & & $\mathrm{x}$ & & & & & & & & [117] \\
\hline GB & Pst TB & & & & & & & & $\mathrm{x}$ & & & & & & & & [123] \\
\hline Ireland & SICCT+ & & & & & & $\mathrm{x}$ & & & & & $\mathrm{x}$ & $\mathrm{x}$ & & & & [125] \\
\hline GB & Ret TB & & & & & & & & & & & $\mathrm{x}$ & & & & & [124] \\
\hline
\end{tabular}




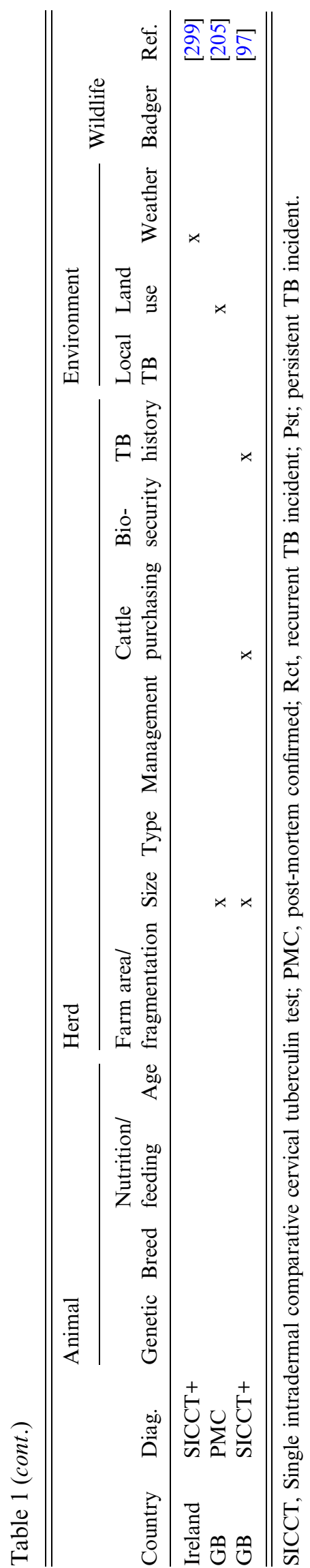

such as restocking after foot-and-mouth disease in 2001 in UK [6, 97, 98] (Table 2) and the influence of trading in England and Ireland has been well reviewed $[72,73,75]$. All report an association between restocking and subsequent increased risk of infection [71, 78, 99-101]. Molecular epidemiology is used increasingly to confirm sources of incidents [102, 103]. The reported percentage of bTB incidents attributed to cattle movements in Ireland, where disease is spread throughout the country, varies from $6 \%$ to $15 \%$ [103-105]. In GB, where disease is clustered in the West and South-West Wales, the proportion of infection attributable to purchased infection is much higher in lower incidence areas. An investigation of 31 incidents in a low bTB incidence area of England found that all but one were most likely due to purchased animals [102]. Prior to legislation requiring the pre- and post-movement testing of cattle imported into Scotland from regions with a high bTB incidence, Scottish farms importing cattle from these regions were almost four times as likely to experience a breakdown than farms that did not. Following the legislation change (2006-2009), this risk, while still significant, had reduced substantially (OR 2.5, 95\% CI 1·03-6.27) [106].

\section{Markets and agricultural shows}

The evidence for a role of markets in bTB disease transmission is inconsistent. Moving animals into herds from markets has been identified as a significant risk factor in GB [6, 71]. One analysis found that herd owners buying cattle from markets had a lower risk of bTB infection than those that did not but this only applied to one region and it was not significant when herds that had been under restrictions, and so could not purchase, prior to the study were excluded [70]. The largest investigation found no relationship between movement or purchasing via markets and bTB in 1544 lesioned, TST reactors compared to matched controls in Northern Ireland [107]. The evidence for a role for agricultural shows in transmission is anecdotal. A descriptive account of an outbreak in the 1970s found that 51 of 56 cattle from 42 herds reacted to the skin test 80 days after being at the same agricultural show [108].

\section{Farm management}

There is evidence that 'good' management and hygiene practices may reduce the risk of $M$. bovis 
Table 2. Studies investigation an association between introduction of stock and bTB incident

\begin{tabular}{|c|c|c|c|c|c|}
\hline Study type & $\begin{array}{l}\text { Study size } \\
\text { (herds) }\end{array}$ & Country/year & Measure of risk & Comment, e.g. market/shows/dispersal & Ref. \\
\hline \multicolumn{6}{|c|}{ Source of stock: type } \\
\hline Case-control & 268 & England & $\begin{array}{l}\text { Logistic regression: } \\
\text { OR } 3 \cdot 26(95 \% \text { CI } 1 \cdot 71-6 \cdot 21) \\
\text { OR } 1 \cdot 93(95 \% \text { CI } 1 \cdot 03-3 \cdot 60)\end{array}$ & $\begin{array}{l}\text { RBCT triplets after initial pro-active badger cull and prior to Jan. } 2001 \\
\text { Markets } \\
\text { Farm sales }\end{array}$ & [71] \\
\hline $\begin{array}{l}\text { Retrospective } \\
\text { cohort }\end{array}$ & 148 & England & Logistic regression: & $\begin{array}{l}\text { RBCT from Oct. } 2001 \text { to Nov. } 2004 \\
\text { Response rate } 40 \% \\
\text { Incidence of } 50 \% \text { over } 3 \text { years } \\
24 \% \text { restocked } \\
\text { Markets }\end{array}$ & [6] \\
\hline $\begin{array}{l}\text { Matched } \\
\text { case-control }\end{array}$ & 218 & $\begin{array}{l}\text { England and } \\
\text { Wales }\end{array}$ & $\begin{array}{l}\text { Conditional logistic regression: } \\
\text { OR } 0 \cdot 18(95 \% \text { CI } 0 \cdot 03-0 \cdot 91)\end{array}$ & $\begin{array}{l}\text { Only confirmed cases. Analysis by region } \\
\text { Market (Taunton) }\end{array}$ & [70] \\
\hline \multicolumn{6}{|c|}{ Source of stock: bovine bTB history } \\
\hline $\begin{array}{l}\text { Retrospective } \\
\text { cohort }\end{array}$ & 4742 & Ireland & $\begin{array}{l}\text { Multivariate logistic regression (GEE): } \\
\text { OR } 1.78(95 \% \text { CI } 1.06-1.55)\end{array}$ & $\begin{array}{l}\text { Slaughterhouse cases excluded } \\
\text { Source herds had incident with SICCT. } \geqslant 8 \text { reactors in previous } 7 \\
\text { months compared to source herd not being under restrictions in last } 7 \\
\text { months }\end{array}$ & [49] \\
\hline $\begin{array}{l}\text { Matched } \\
\text { case-control }\end{array}$ & 218 & $\begin{array}{l}\text { England and } \\
\text { Wales }\end{array}$ & $\begin{array}{l}\text { Conditional logistic regression: } \\
\text { OR } 0 \cdot 93(95 \% \text { CI } 0 \cdot 96-0 \cdot 99) \text { per } \\
\text { additional } 10 \% \\
\text { OR } 1 \cdot 90(95 \% \text { CI } 1 \cdot 0-3 \cdot 62) \\
\text { OR } 8 \cdot 48(95 \% \text { CI } 2 \cdot 23-32 \cdot 2)\end{array}$ & $\begin{array}{l}\text { Case used confirmed and unconfirmed } \\
\text { Proportion sourced from 4yrly testing interval } \\
\text { Sourcing from herd with incident within previous } 2 \text { years } \\
\text { Sourcing form herd with incident in previous } 2 \text { years } \\
\text { (Stafford data only) }\end{array}$ & [70] \\
\hline Case-control & 18670 & GB & $\begin{array}{l}\text { OR } 1 \cdot 35(95 \% \text { CI } 1 \cdot 22-1 \cdot 49) \text { per every log } \\
\text { increase in number of cattle introduced }\end{array}$ & $\begin{array}{l}\text { Number of cattle brought form yearly testing interval compared } \\
\text { to not purchasing }\end{array}$ & [97] \\
\hline \multicolumn{6}{|c|}{ Type of stock introduced } \\
\hline Case-control & 160 & $\begin{array}{l}\text { Ireland, } \\
1986-1990\end{array}$ & $\begin{array}{l}\text { Conditional logistic regression: } \\
\text { OR } 3.9(95 \% \text { CI } 1 \cdot 2-12 \cdot 4)\end{array}$ & $\begin{array}{l}\text { Matched on herd size. Cases under restrictions for } 12 \text { months } \\
\text { Purchasing a bull in previous } 5 \text { years }\end{array}$ & [95] \\
\hline $\begin{array}{l}\text { Comparative } \\
\text { case-control }\end{array}$ & 229 & UK, 1995-1999 & OR $4.9(95 \%$ CI $1 \cdot 1-22 \cdot 8)$ & $\begin{array}{l}\text { Risk of persistent incident ( }>6 \text { months) when introducing adult cows } \\
\text { compared to store, calves and no introductions }\end{array}$ & [93] \\
\hline Case-control & 102781 & Ireland, 2006 & OR 1.04 (1.03-1.05) & $\begin{array}{l}\text { Incident defined as the presence of one reactor to the SICCT. } \\
\text { Introduction of stock }>1 \text { year in the previous year }\end{array}$ & [96] \\
\hline \multicolumn{6}{|c|}{ Number of stock introduced } \\
\hline $\begin{array}{l}\text { Comparative } \\
\text { case-control }\end{array}$ & 229 & UK, 1995-1999 & $\begin{array}{l}\text { Multivariate logistic regression: } \\
\text { OR } 4 \cdot 0(95 \% \text { CI } 1 \cdot 0-16 \cdot 0)\end{array}$ & $\begin{array}{l}\text { Risk of transient incident ( }<6 \text { months) } \\
\text { Comparing introduction of }>50 \text { cows to }<50 \text { cows }\end{array}$ & [93] \\
\hline Case-control & 62 & $\begin{array}{l}\text { Argentina, } \\
2005-2007\end{array}$ & $\begin{array}{l}\text { Logistic regression } \\
\text { OR } 3 \cdot 3(95 \% \text { CI } 1 \cdot 1-10 \cdot 2)\end{array}$ & $\begin{array}{l}\text { Pastoral systems, herd size } 50-500 \text {. Using caudal fold test. Cases }>4 \\
\text { reactors, Controls no reactors in } 24 \text { months } \\
>19 \text { heifers introduced into the herd in } 3 \text { years }\end{array}$ & [79] \\
\hline
\end{tabular}

OR, Odds ratio; CI, confidence interval; RBCT, Randomized Badger Culling Trial; SICCT, single intradermal comparative cervical tuberculin test. 
transmission, particularly in developing countries [109-113] but also in Europe [114, 115]. In Spain, the communal use of equipment (cattle race) between herds was positively associated with a positive TB test [115]. In GB, poor dairy herd management such as; farm buildings and feed stores being accessible to badgers, allowing grazing at field margins and grazing in fields with badger activity were associated with an increased risk of bTB [114].

Intensive management practices that increase cattle to cattle contact within a herd are associated with an increased risk of bTB incidents [116]. Case-control studies have found dairy herds kept in cubicle housing [95] and covered yards [71] have a substantially increased risk of bTB. This type of housing may be a proxy for the effects of greater stress or reflect a more intensive management system that increases cattle contact rates. This is supported by studies in GB that found the presence of a loafing yard or paddock adjoining cattle housing [114] and not providing housing for cattle [75] reduced the risk of bTB. The use of barns in which cattle can move freely was associated with a positive SICCT test in Spain; the aggregation of cattle within the barn increasing both direct and indirect contacts [117].

Rough grazing in Ireland [95], set stocking in England [70] [114] and grazing cattle on sown or ley pasture [114] have all been associated with an increased risk for bTB in multivariate analyses controlling for herd size. Feeding from the ground either at pasture or during housing [115], storing silage in clamps [93] and feeding green foods/kale or barley have been associated with an increased risk of a bTB incident [114]. These findings could be potentially attributed to increased contact with wildlife. Silage, in particular maize silage [118] is attractive to badgers, and was found to be associated with badgers entering farm buildings in one study [119], but visits to silage clamps were rare in another larger scale study [120]. The storage and feeding of silage from clamps is associated with persistent breakdowns [93] potentially related to the clamps being more accessible to badgers. Feeding hay rather than silage/concentrates has been reported as protective [93, 95, 121], and a casecontrol study found herds fed silage had a greater risk of a breakdown [116]. In one study, all farms that experienced a persistent breakdown were fed grass silage, although $85 \%$ of the TB-free farms also did so [93].

Three studies have found that nutritional supplementation lowers the herd-level risk of bTB. Farms with areas of rough grazing that did not supply mineral licks were up to 30 times as likely to be infected with bTB, although with wide $95 \%$ CIs (1.46-594.4) suggesting it should be interpreted with caution [95]. Two further studies in England support the finding, however, as the provision of protein supplement blocks [114] and vitamin and mineral licks [6] were protective.

There is some evidence, although none from the UK and Ireland, of an increased risk of transmission of $M$. bovis infection to calves fed raw milk or colostrum. However the evidence as to its contribution to bTB risk within the context of an ongoing control program is weak. A case-control study in Argentina found no increased risk in herds feeding raw milk, but did find a higher risk in herds where weaning had been delayed for 4 days, which could be attributed to either drinking infected colostrum or increased exposure to an infected dam [79]. In Spain, bTB incidents in herds where calves were fed replacement milk from test-positive dams were more likely to be persistent but this verged on significance [92].

\section{Other domestic species}

While $M$. bovis has been isolated from a range of nonbovine domestic species in GB [122], they are not thought to represent a substantial risk to cattle. Few studies have directly examined the risk they pose and no clear trend has been identified [92, 123, 124]. In Spain, bTB incidents were almost four times more likely to be persistent if goats were present on the farm, although only a small number of farms were affected $(N=11)$ while incidents in herds that also farmed pigs were more likely to be resolved quickly [92]. Conversely, contact with any domestic species from a non-contiguous farm was associated with an increased risk of a prolonged incident in GB [123].

\section{bTB HISTORY AND TESTING}

\section{bTB history in the region and herd}

Local geographic areas with a history of bTB have been consistently identified as being at significantly higher risk of future incidents than other areas $[100$, 103, 125-127]. The origins of recurrent infection are difficult to separate. There may be a failure to detect and remove all infected cattle or there may be repeated reinfection of the herd through exposure to one of several risk factors which might include infected cattle in 
contiguous herds, local movements and exposure to other wildlife or environmental sources of $M$. bovis. Evidence that reinfection can cause recurrent bTB in GB has come from studies of bTB incidents in herds after complete depopulation and restocking, ruling out infection persistence within the herd [97, 128]. In Ireland, herds depopulated for bTB control were no more likely to have a further bTB incident than herds that had been depopulated because of BSE control, but localized badger culling prior to depopulation had occurred in the bTB herds [129].

The number of reactors or the duration of previous bTB incidents is also associated with future risk at a herd level $[82,83,123,125-127,130]$ and also at an animal level [131, 132]. Post-mortem evidence of infection in cattle in the original incident has been positively associated with a higher future incident risk in at least one study in Ireland [125], although in others no such relationship has been found [82, 123, 126, 130]. Mathematical modelling of recurrence of bTB within a herd estimated that around $24-50 \%$ of recurrent incidents are attributable to persistence of infection in the herd, depending on the length of the assumed latent period [76].

In some countries including GB, inconclusive reactors (IRs) are re-tested and, depending on the result, either remain in the herd or are culled. Follow up of IRs has found that they are more likely to have post-mortem evidence of infection than cattle that had a negative response to the skin test [133]. Furthermore, IRs that re-tested negative and remained in the herd were almost four times more likely to be diagnosed with bTB at a later date [134].

\section{Persistence and test performance}

Recurrence and infection persistence in a herd may indicate failure of testing, thereby allowing infected animals not only to remain in the population, but potentially to continue to spread infection. Several factors have been identified that influence test performance and hence possible failure to detect infection:

(1) Intrinsic test sensitivity. Diagnostic accuracy varies between different types of tests and tests currently approved for bTB in Europe are considered to have fairly moderate sensitivity and variable specificity [135]. Potency of the tuberculin (purified protein derivative; PPD) may also affect the sensitivity and specificity of tests that rely on this biological product such as TST and the IFN- $\gamma$ blood test [136-138].

(2) Choice of diagnostic cut-off. The interpretation of the SICCT test relies on comparing the difference in size between the reaction to avian tuberculin and bovine tuberculin. Altering the cut off for a reactor from $>4 \mathrm{~mm}$ size difference (standard interpretation) to $>2 \mathrm{~mm}$ (severe interpretation) increases the sensitivity of the test and decreases specificity [139].

(3) Rigorous test procedure. Qualitative research has identified several key issues that may influence the quality of testing, including on-farm conditions, tester training and experience, and the conflict of interest in the relationship between private veterinarians and the farmer [140]. Some breeds of cattle may pose testing difficulties that can cause decreased sensitivity, for example bullfighting cattle in Spain [85]. Considerable variation has been found between veterinarians in their application of the comparative test [141], although this study was in Belgium, which has had 'officially tuberculosis free' status since 2003 and so TB testing would be relatively infrequent. Differences in test protocol have also been shown to influence the IFN- $\boldsymbol{\gamma}$ test [142]. In Ethiopia, higher throughputs in abattoirs have been associated with lower lesion detection in routinely slaughtered cattle [143].

(4) Disease stage in the animal. bTB is a chronic, slowly progressing disease. The sensitivity of abattoir surveillance based on detection of visible lesions increases with disease advancement [143]. While the TST detects early immunological changes associated with infection, there is still a delay, with earliest detection being estimated at between 21 and 50 days post-infection [10, 136]. During the late stages of the infection, particularly in severe and generalised disease, responsiveness to the skin test is reduced (anergy) [10, 143, 144]. During anergy, the infection is likely to be systemic and severe, cattle are potentially more infectious thus increasing the significance of inadequate detection.

(5) Desensitization to the test. The majority of studies reviewed, but not all [10], have shown that the responsiveness to tuberculin is reduced for up to 60 days after the skin test $[136,145]$. Some evidence suggests that a TST may increase the sensitivity of subsequent IFN- $\boldsymbol{y}$ tests [146], although findings tend to vary $[142,147]$. Immunosuppression due 
to stress, comorbidity, advanced tuberculosis or calving may also lead to variation in reactivity to tests [51, 145, 148, 149].

(6) Host or pathogen genetic variation. There is some evidence that some cattle may be genetically predisposed to pass the standard TST used in GB [150]. However, in an extensive study (21 000 isolates) in Northern Ireland, no association between skin test response and $M$. bovis genotype was detected, after controlling for confounding factors [151].

(7) Cross-reactivity. A diverse range of saprophytic mycobacteria exist in the environment, which although they rarely cause disease in cattle, are significant in immunological diagnosis. For example, $M$. avium [152-154], M. fortuitum [155] and $M$. kansasii [156-158], may all interfere with the interpretation of diagnostic tests for M. bovis. Such bacteria can cause animals to react to bovine tuberculin and hence be interpreted as a falsepositive bTB diagnosis, or otherwise interfere with test interpretation $[144,155,156,159]$. Conversely, it has been shown experimentally that a genuine positive response to bovine PPD can be masked by a larger or commensurate response to avian PPD [153, 157, 160, 161], suggesting that $M$. bovis infection may be concealed for some time in cattle sensitized by mycobacteria of the avium/intracellulare complex, thus preventing detection and removal.

(8) Concurrent infection. There is accumulating evidence that concurrent infection with $F$. hepatica and with MAP may affect the performance of immunological tests for bTB infection. Evidence suggests the immunomodulatory effects of the helminth $F$. hepatica may reduce the sensitivity of immunological diagnostic tests for tuberculosis $[63,65,109,162]$. Stronger skin responses to tuberculin tests have been reported in cattle that had been dewormed compared to animals that had not, although bTB infection status was not determined [163]. Cross-reactivity of some proteins shared between $M$. bovis and MAP, can impede diagnosis of bTB in concurrent infections [164-168]. False-positive bTB diagnoses, by the caudal fold test, have been recorded in animals that tested positive for MAP either by the detection of MAP in their faeces or a positive ELISA [166]. Conversely, infection with MAP has been known to obscure the detection of M. bovis in concurrent infections in Spanish cattle [167]. Vaccination against MAP can interfere with immunological methods of bTB diagnosis in cattle [169-172] although, in one study, animals vaccinated with an inactivated MAP vaccine in field trials showed cross-reactivity to the single intradermal tuberculin test (SIT) but not to the SICCT [173]. Despite its limitations, serology has been used to distinguish TB-free cattle that have been vaccinated against Johne's disease [174].

\section{LANDSCAPE, CLIMATE AND OTHER ENVIRONMENTAL RISK FACTORS}

\section{Survival and persistence of $M$. bovis in the environment}

Estimates of environmental survival of $M$. bovis, evaluated for artificial and natural contamination of several sites and substrates are extremely variable, ranging from a few days to 2 years [175] (Table 3). Much of the data derives from early studies in GB and other countries where levels of natural environmental contamination may have been high, given the abundance of clinically advanced bTB in cattle. In general, tubercle bacilli survive best in cool, moist environments shaded from direct sunlight and survival depends on temperature, sunlight and relative humidity (Table 3). Longer survival times in winter compared to summer months have been recorded for $M$. bovis in experimental studies conducted in GB [176], New Zealand [177], Michigan [178] and Australia [179] (Table 3). M. bovis remained viable up to twice as long in shady conditions compared to sunny conditions [180].

Experimental studies demonstrate that $M$. bovis can be isolated $>5$ months after inoculation when mixed with faeces [176] and after one month in spiked possum carcasses [181]. Viable bacteria were recovered from hay at 7 days after inoculation and could still be isolated from samples of apples, corn and potatoes after 112 days [182]. In silage, the survival of M. bovis is likely to be shortened by the acidity ( $\mathrm{pH}$ reduction) and temperature during fermentation. When silage containing large quantities of naturally infected faeces was fed to guinea pigs, it was infective for up to 10 weeks postinoculation (Ulli Reuss, 1955 quoted in [80]).

Farm practices relating to both the storage and spreading of slurry can increase the risk of a herd bTB incident $[6,93,95,183]$ and the role of slurry in the transmission of bTB has recently been evaluated [184]. M. bovis can persist in slurry for up to 6 months $[183,185]$ and spreading of slurry after storage for $<2$ months has been associated with an increased 
Table 3. The effect of environmental variables on the survival of $\mathrm{M}$. bovis

\begin{tabular}{|c|c|c|c|c|}
\hline Conditions & Exposure & Survival & Detection by & Ref. \\
\hline \multicolumn{5}{|l|}{ Temperature } \\
\hline Mixed with faeces in open air (Berks) & $\begin{array}{l}\text { Winter from November } \\
\text { Autumn from September } \\
\text { Summer from June }\end{array}$ & $\begin{array}{l}\geqslant 5 \text { months } \\
4 \text { months } \\
<2 \text { months }\end{array}$ & $\begin{array}{r}\text { Guinea pig } \\
\text { infectivity }\end{array}$ & {$[176]$} \\
\hline Mixed with faeces or soil (Berks) & Summer from June or May & 5 months & & {$[300,301]$} \\
\hline Absorbed onto cotton ribbon (New Zealand) & $\begin{array}{l}\text { Winter and spring } \\
\text { Summer }\end{array}$ & $\begin{array}{l}>14,<28 \text { days } \\
<7 \text { days }\end{array}$ & & [177] \\
\hline In the laboratory & $\begin{array}{l}0{ }^{\circ} \mathrm{C} \\
16^{\circ} \mathrm{C}\end{array}$ & $\begin{array}{l}50 \% \text { at } 36 \text { days } \\
50 \% \text { for }<1 \text { day }\end{array}$ & Culture & [302] \\
\hline In soil, water, hay or maize (Michigan, USA) & $\begin{array}{l}\text { Autumn and winter } \\
\text { Winter and spring } \\
\text { Spring and summer }\end{array}$ & $\begin{array}{l}30 \pm 13 \text { (s.D.) days } \\
29 \pm 26 \text { days } \\
6 \cdot 9 \pm 12 \cdot 5 \text { days }\end{array}$ & Culture & {$[178]$} \\
\hline In possum carcasses on pasture (New Zealand) & $\begin{array}{l}\text { Winter } \\
\text { Summer }\end{array}$ & $\begin{array}{l}20-27 \text { days } \\
<3 \text { days }\end{array}$ & & [181] \\
\hline \multicolumn{5}{|l|}{ Moisture } \\
\hline In the laboratory & $\begin{array}{l}100 \% \text { relative humidity } \\
57 \% \text { relative humidity } \\
5 \% \text { relative humidity }\end{array}$ & $\begin{array}{l}50 \% \text { at } 43 \text { days } \\
50 \% \text { at } 8 \text { days } \\
50 \% \text { for }<1 \text { day }\end{array}$ & Culture & {$[302]$} \\
\hline $\begin{array}{l}\text { In faeces, dry soil and moist soil in Tropical } \\
\text { Australia }\end{array}$ & Shaded conditions & $\begin{array}{l}\text { Favourable for } \\
\text { survival }\end{array}$ & & [179] \\
\hline \multicolumn{5}{|c|}{ Ultraviolet radiation (including solar radiation) } \\
\hline $\begin{array}{l}\text { Mixed with faeces in open air (Berks) } \\
\text { (September) }\end{array}$ & $\begin{array}{l}\text { Exposed } \\
\text { Shaded and sheltered from } \\
\text { rain }\end{array}$ & $\begin{array}{l}4 \text { months } \\
6 \text { months }\end{array}$ & $\begin{array}{r}\text { Guinea pig } \\
\text { infectivity }\end{array}$ & [176] \\
\hline In the laboratory & UVA radiation $(375 \mathrm{~nm})$ & $80 \%$ for $20 \mathrm{~min}$ & Culture & [302] \\
\hline
\end{tabular}

risk of bTB [105]. Experimental studies have demonstrated that $M$. bovis can remain viable for up to 12 $\mathrm{h}$ after aerosolization and the bacteria is resistant to stresses of being airborne [186]. Methods that reduce the distance over which slurry is dispersed and injecting slurry into soil, rather than spraying under pressure, reduces the risk of drift [183].

M. bovis has been recovered from soil sampled from badger setts and fields on a farm in Ireland that had a recent TB incident [187] and was isolated from one water sample from yards frequented by infected badgers in England [188]. In the United States, despite extensive sampling, M. bovis was not detected in soil, water, livestock bedding, feed, faeces, hay, pasture and grass samples collected from farms in Michigan and Texas recently positive for bTB [189-191]. However, prevalence in cattle and in local wildlife, including white-tailed deer (Odocoileus virginianus) $(<2 \%)$, was much lower than apparent M. bovis prevalences in badgers that have been recorded in GB and Ireland (14-16\%) and infection in cattle populations was also lower [192-195].

Estimating the extent of environmental contamination with $M$. bovis may be confounded by the practical difficulties inherent to its isolation and culture from environmental samples [175, 190]. Procedures for concentrating bacteria from larger samples are required to compensate for the patchy distribution of bacteria in environmental samples [189]. Molecular methods specific to M. bovis have been developed to detect and quantify mycobacterial DNA in environmental samples [196, 197] although they have limited sensitivity and positive results do not necessarily indicate viability or infectivity. On the other hand, DNA in dead cells did not survive beyond 10 days, suggesting that the DNA extracted from environmental samples may have come from intact cells [187].

\section{Weather and climate}

Wint et al. [198] were able to predict the geographical distribution of bTB in England and Wales with a high level of precision (kappa $=0.68)$ using monthly remote-sensing data for weather-related variables (resolution $1-5 \mathrm{~km}$ ) and cattle density. These variables were more important predictors than land use or vegetation. Areas with the greatest risk of bTB were more moist, having a lower water vapour pressure deficit 
(VPD). They also had their peak VPD later in the year and had lower variability of VPD and temperature. Recently, Jin et al. [299] were able to predict bTB incidence from rainfall over a 5-year period in an area of Wicklow, Ireland; the strongest correlations being with rainfall one or two quarters before the breakdowns. However, a previous study from Ireland failed to consistently predict the incidence of bTB reactors over 15 years using a range of weather variables [299]. The North Atlantic Oscillation (NAO), a major determinant of weather conditions in Western Europe, has been shown to be a significant correlate of culled badger M. bovis prevalence, but its inclusion in statistical models left a great deal of unexplained inter-annual variation which was better explained by the effect of the 2001 foot-and-mouth disease outbreak [200].

Flood and drought could affect the risk of infection with bTB by influencing the survival of $M$. bovis (Table 3) or by affecting contact patterns between cattle and other cattle or infected wildlife but there is little published evidence for any relationship between flooding in temperate climates. It has been hypothesized that, in times of drought, badgers may resort to woodlands for prey in moist leaf litter and their contact with cattle would be reduced [201]. In Africa, associations between increased bTB prevalence and flooding have been attributed to enforced contact between herds [202], and with drought as it forces cattle to use communal water sources shared by infected and naïve cattle [203] and encourages large-scale movements [204].

\section{Landscape}

A number of landscape and environmental factors have been found to be associated with increased or decreased herd bTB incidents, although the degree of association varies [93, 100, 116, 205-207].

Many landscape factors identified determine the suitability (or otherwise) of an area for badgers or act as barriers for the geographical spread of bTB [208]. Landscape characteristics such as altitude and habitat composition are correlated with badger abundance [209, 210]. Soil type has also been associated with badger abundance [211, 212] with badgers preferring sandy loamy soils for sett construction. Interestingly, soil characteristics also correlate with bTB risk, with bTB-affected farms being less likely to have deep clay soils or seasonally wet soil [70] and $M$. bovis was more likely to be isolated from sandy soil in cattle farms in Michigan [213]. This soil type may provide a moist, well drained microclimate that could maintain suitable $\mathrm{pH}$ and moisture levels that favour bacterial survival.

The distribution of badger latrines in a high density population in South-West England varied according to habitat types and landscape features [214]. Latrines are generally more commonly found in woodland and are less common in arable or grassland [214, 215]. A high proportion of latrines are located within $5 \mathrm{~m}$ of a linear feature (especially hedges and stone walls) [214] or are associated with runs crossing such linear features [209].

Higher densities of hedgerows [205] and a higher percentage of boundaries composed of hedgerows [116] on a farm were associated with a reduced risk of a bTB incident in the resident herd. The authors suggested that this was because longer forage (preferred by grazing cattle) is associated with higher hedgerow density and thicker hedgerows may mean that cattle cannot access areas that may be more contaminated with badger faeces and urine.

\section{Water sources}

Aggregation at communal water sources encourages closer contact between cattle and may increase the likelihood of contact with wildlife, although there is little evidence for a risk pathway in GB. Evidence from Spain found farms with high density of streams had a lower risk of TB, thought to arise because dispersed water resources reduced aggregation of cattle and wildlife [115]. The presence of water sources (ponds and creeks) with uncontrolled access has been associated with an increased risk of bTB in Michigan, USA [207] and in Western Uganda [216].

\section{Transmission through birds, invertebrates and protozoa}

Mechanical transfer of $M$. bovis bacteria on the feet of birds [189] or via invertebrates [217] is considered a theoretical risk although has yet to be demonstrated. $M$. bovis has been isolated from various species of birds in Europe, although they were predominantly birds of prey [218]. A report from the Soviet Union describes $M$. bovis and M. avium in several species of tick [219]. M. bovis has also been detected in horn flies (Haematobia irritans) [220].

Experimental studies have demonstrated that $M$. bovis can survive in protozoa (Acanthamoeba castellanii), potentially facilitating transmission by extending the survival of the bacteria in the soil [221]. However, co-incubation of both organisms under laboratory 
conditions substantially reduced levels of bacteria, suggesting that while there is the theoretical potential for environmental amoebae to act as a reservoir of $M$. bovis, they may also reduce environmental contamination [222]. Acid-fast microorganisms have been observed inside amoebae isolated from infected badger setts, although attempts to confirm them as $M$. bovis by culture or PCR were unsuccessful [222].

\section{WILDLIFE}

\section{Badgers}

In the UK and Ireland the European badger (Meles meles) is the main wildlife reservoir for bTB infection in cattle. A reservoir is defined as a epidemiologically connected population in which infection is permanently maintained and transmitted to a target population [223]. Furthermore, this reservoir of infection in badgers is often cited as the main barrier to eradicating infection in domestic livestock in these countries. The most compelling evidence of the infection risk that badgers pose to cattle comes from large-scale trials in the UK and Ireland, where badger culling had significant impacts on the incidence of bTB in cattle [224227]. Within the boundaries of proactively culled areas during the Randomized Badger Culling Trial (RBCT) cattle bTB incidence was reduced by $33 \%$ after four annual rounds of proactive culling [227]. Given that not all badgers were culled [228], this is likely to represent a minimum number of incidents that are attributable to badgers in these areas. More recent analyses of the RBCT data suggests that in an endemic area, badgers are directly responsible for $6 \%$ of bTB infections in cattle and the overall contribution from badgers, through onward cattle to cattle transmission, is $\sim 50 \%$ [229]. How badgers transmit bTB to cattle is not known, although several likely routes are described below.

\section{Proximity and abundance of badgers}

Presence and abundance of badgers near cattle farms have been included in a range of analyses of potential bTB risk factors. Analyses of risk factors associated with cattle herd incidents that include the distance from farm buildings to badger setts have produced conflicting results. Johnston et al. [71] found that including presence of occupied badger setts within 1 $\mathrm{km}$ of farm boundaries did not improve their bTB risk prediction models, and Griffin et al. [88] likewise observed that the distance to badger setts did not vary relative to bTB incidents in herds. Conversely, Martin et al. [230] found a significant, though weak, reduction in the risk of an incident with increasing distance to badger setts and [89] found positive associations between the presence of badgers and herd incidents in Northern Ireland. In South-West England, finding dead badgers on a farm was associated with a threefold increase in the risk of a bTB incident [70].

Studies investigating cattle bTB risks in relation to local badger density have also produced mixed results. For example, Reilly \& Courtenay [93] reported an association between high densities of badger setts and persistent cattle herd incidents, but only after adjusting for farm management-related variables. Similarly, another study reported a correlation between the number of active badger setts within $1500 \mathrm{~m}$ of a farm and the probability of cattle herd incidents [91]. However, a study by Mathews et al. [205] found little evidence of an association between badger density and bTB risk, as farms with management practices that favoured wildlife had a lower risk of bTB.

\section{M. bovis transmission routes}

Badger-to-cattle transmission has been experimentally demonstrated [188], but the principal routes of transmission in the field can only be inferred at present. Infected badgers may excrete $M$. bovis bacilli in urine, faeces, sputum and exudate from open abscesses [231]. Studies have identified $M$. bovis in soil and latrines [232], and there is evidence for bacilli remaining infectious for some time after being deposited, at least in certain environmental conditions [233].

Potential routes of transmission include direct transfer via very close contact between badgers and cattle, and indirect contact where cattle encounter infectious material from badgers. Both mechanisms could theoretically occur at pasture or in farm buildings, but the relative importance of these transmission routes is unknown. As smaller numbers of bacilli are needed to infect cattle via the respiratory system than via the digestive system [50], inhalation of bacteria is likely to be the main route of infection [234]. This could occur during nose-to-nose contact with badgers, but also while grazing, as cattle aerosolise and inhale bacilli on contaminated pasture or forage.

\section{Direct transmission risks}

Previous observational studies suggested that close contact between badgers and cattle at pasture is unlikely [235] and other research suggests that badgers 
may actively avoid pasture with grazing cattle [236]. Studies using proximity loggers have shown that close contact between badgers and cattle does occur at pasture although it was reported as relatively infrequent [61] or very rare [81, 237]. The available evidence suggests that direct contact at pasture is unusual, although contact rates could vary across different landscapes. Badgers may frequently visit farm buildings, where they may readily come into close contact with cattle [119, 238-240]. The evidence from several studies suggests that direct contact may be more frequent in buildings and it has been suggested that it may be easier to reduce risks by modifying buildings to exclude badgers [238, 241].

\section{Indirect transmission risks}

Badgers habitually defecate and urinate at latrines [242] This may concentrate potentially infectious material and give rise to enhanced infection risk to cattle at certain locations, although it may conversely reduce risks elsewhere [243]. Early research suggested that cattle avoided grazing on pasture contaminated by badger faeces [235, 244]. However, subsequent studies showed that cattle would explore contaminated pasture, and a small proportion would graze at latrines [245]. Visits by cattle to badger latrines recorded by proximity loggers found that $85 \%$ of the cattle in one herd actively investigated badger latrines and $15 \%$ of them visited latrines over 100 times in a 6-month period [237]. The extent to which this occurs may be affected by farm management practices such as grazing rotation patterns [244] which in turn influence factors such as sward height [245].

Badger urine may present a significant bTB transmission risk to cattle as it can contain up to 300000 bacilli/ml [209, 246]. Grazing cattle do not appear to avoid badger urine deposited away from latrines [209, 247], which often occurs on runs crossing linear features such as hedgerows [209]. Cattle have been shown to graze readily at such crossing points, and elsewhere on pasture contaminated with badger urine [209, 245].

Badgers have been observed both defecating and urinating onto stored cattle feed in farm yards, buildings and cattle troughs $[119,240,248]$. Cattle have been recorded showing little or no avoidance of feed contaminated with faeces from rodents and wild birds [249]. It has been suggested that this non-selective feeding behaviour may represent a bTB transmission risk especially if the contaminated feed is well-mixed.
One questionnaire-based study provided some support for this hypothesis, finding a significant positive association between the perceived reported presence of badgers in feed stores or cattle housing and an increased risk of cattle herd incidents [227].

\section{Wild boar}

M. bovis infection has been isolated from wild boar in several European countries [250-257], including in a feral wild boar (Sus scrofa) in the UK [258]. Research on the Iberian Peninsula has reported bTB prevalence of up to $52 \cdot 4 \%$ [259] and positive associations between the density of wild boar populations and cattle bTB incidence [260, 261]. The presence of wild boar on cattle farms in Spain, as reported in farmer questionnaires, was associated with TB breakdowns [115]. Furthermore, the M. tuberculosis complex genotypes found in wild boar are of the same origin as the bovine and caprine genotypes found in domestic swine, deer and humans [259, 262, 263]. Hence, there is evidence to support the role of the wild boar as a reservoir host of $M$. bovis in Mediterranean areas (reviewed in [264]). In the UK, wild boar have a limited geographical distribution, mainly confined to small areas in Kent/Sussex and Gloucestershire/Herefordshire. Therefore, the current risk to livestock from this species in the UK is considered to be low, although this has the potential to change should wild boar numbers and geographical distribution change. There is currently no empirical data on the growth trajectory of wild boar populations in the UK. This species has a very high reproductive rate for an ungulate and hence the potential to increase population size rapidly [265], although hunting and restricted woodland cover may constrain their numbers and distribution in the UK [266].

\section{Deer}

Several wild deer species in Europe have been found to be susceptible to bovine bTB infection, including fallow (Dama dama), roe (Caprolus capreolus), red (Cervus elaphus), sika (Cervus nippon), Reeves' muntjac (Muntiacus reevesi), reindeer (Rangifer tarandus) and elk (Alces alces) [218]. Spatial associations between strain types in deer and cattle have been demonstrated by restriction fragment-length polymorphisms in Ireland [267] and by spoligotyping in Spain [268], suggesting that bTB is transmitted between these species. Furthermore, experimental studies have 
demonstrated that indirect transmission of bTB could occur between white-tailed deer (Odocoileus virginianus) and cattle through sharing of feed [269]. Spatially explicit modelling of density and distribution of white-tailed deer and cattle herds with bTB breakdowns in Michigan, USA, demonstrated that infected deer play an important role in the maintenance of bTB in that area [213].

In a case control study in Michigan, USA, Kaneene et al. [207] found that the prevalence of bTB in the local deer population was an important risk factor for bTB in cattle. They also found that bTB risk was increased when water was provided to cattle outdoors and large quantities of hay bales were stored in fields or on pasture fence lines. Conversely, the risk was reduced if feed was stored indoors or properly protected by bagging or wrapping. A semi-quantitative assessment of the risk of transmission from deer to cattle in the UK, based on prevalence of infection, extent of potential bacterial excretion, likelihood of contact with cattle and approximate biomass suggested that red and particularly fallow deer represented the greatest potential risk. However, any risk is likely to be localised given the geographical variation in deer densities [270].

\section{Other species}

M. bovis has a wide host range and is the most common cause of tuberculosis in mammal species [271]. $M$. bovis infection has been identified in numerous wild mammal species in the UK (see [271]), although a semi-quantitative risk assessment suggested that species other than deer and badgers are unlikely to pose a significant risk of bTB transmission to cattle [270].

\section{HUMAN-TO-CATTLE TRANSMISSION}

There are a large number of documented cases of human to cattle transmission from the first part of the 20th century in Europe, in Denmark [272], the UK [273], Germany [274-277], The Netherlands [148]. However a case was reported relatively recently in Switzerland [278]. More recently, associations between tuberculosis in humans and cattle have been predominantly documented in Africa [202, 279-282].

\section{DISCUSSION}

We present an overview of risk factors that have been identified for bTB in cattle, with a primary focus on the UK and Ireland, but where gaps exist drawing on evidence from further afield. However, there are difficulties in extrapolating from many studies and in weighting the relative importance of the various risk factors identified in the literature owing to differences in study design, circumstances, follow-up time, selection criteria and case definitions. Variation in herd composition, management, history of infection and local circumstances, including exposure to potential sources of infection from wildlife, will all vary in space and time creating serious challenges for between study comparisons. The case definition for a bTBinfected herd in Europe is detection of one or more reactors to the SIT or SICCT test (64/432/EEC) at standard interpretation but definitions in the literature range from other interpretations of the skin test [44, 48, 93] to laboratory-confirmed M. bovis infection [207], or to the detection of reactors with evidence of infection [89]. The principal outcomes examined also varied from detection of infection to disease characteristics such as duration [123], chronic persistence [92] and recurrence [82, 83, 124] (Table 1). This range supports the use of a review of evidence from several studies looking at similar research questions over a relatively broad geographical range.

Nevertheless, despite differences in study design some clear and consistent patterns have emerged across a broad range of infection prevalence and environments. Prominent are the increased risks associated with animal age, contact with a wildlife reservoir and the size of the herd. Purchasing strategies and management practices that favour intensive production, also promote increased contact among cattle (housing) and with wildlife (fragmentation, farm size) at the expense of hygiene and biosecurity. Herds with a history of bTB are consistently identified as being at higher risk of a future bTB incident. The relative importance of different risk factors also varies according to incidence. In low-incidence areas, infection is predominantly related to cattle movements [103, 106]. In higher risk areas, risk factors reflect increasing contact rates, as is unsurprising for a contagious disease, e.g. herd size, farm size, movements, housing, and exposure to wildlife (Table 1).

Causality between markers for infection or disease and many risk factors cannot be assumed. Many risk factors may act as proxies for contact and transmission opportunities or other unmeasured variables. Landscape characteristics will influence the distribution and abundance of wildlife and reflect different cattle management practices, and so may be proxies for contact rates among cattle and between cattle 
and wildlife. Also, the quality of animal husbandry may affect the level of $M$. bovis contamination and attitudes to biosecurity. Hence, the significance of the reported protective association between vitamin and mineral supplementation and bTB [6, 55, 95, 114] may be a proxy for poor management and hygiene practices on infected farms. More research is needed to determine the impact and relative contribution of management factors, such as nutrition and housing on infection transmission and pathogenesis within the host animal.

The risk that bacilli released into the environment by infected cattle or wildlife will infect other animals depends on the rate at which they lose their viability and virulence. Survival of $M$. bovis in soil and other environmental substrates depends on temperature, moisture, $\mathrm{pH}$, exposure to sunlight, oxygenation, and interactions with other microflora, and so will be expected to vary widely in space and time. Such environmental factors have been associated with variation in the risk of bTB in cattle [183].

\section{Knowledge gaps and the way forward}

The relative importance of the risk factors identified to date are likely to vary among farms and environments, and over time making it difficult to identify generic patterns. Many risk factors have been identified in relation to different types of herd management such as sharing of equipment [115] and types of housing [71, 95], but their impact is unknown. In many studies once location, bTB history and herd size are accounted for, the degree to which management factors may influence the risk of an incident is low. The calculation of the population attributable fraction in bTB risk factor studies is relatively rare, but can provide an assessment of the absolute contribution of a risk factor to infection incidence or prevalence $[71,96,138]$. It can be used to provide a measure of how many bTB cases might be prevented by modifying or removing a risk factor or range of factors. If prevalence of the exposure is low, then the relative importance of the risk factor will be low, even if the association with disease is quite strong.

Few risk factor analyses have matched cases and controls on herd size [70] but the dominance of herd size in many risk factor studies (Table 1) [73, 75, 283], supports a case for conducting studies matched on herd size, to attempt to tease out other management characteristics that may be a feature of large herds and may promote infection transmission.
In the UK and Ireland there is a large body of evidence to support transmission from badgers to cattle [224-227, 230, 284] and transmission is likely to be reciprocal [285] suggesting that in at least some circumstances the two populations may constitute a host community in which $M$. bovis circulates. Hence there is the potential for interactions and interdependency among cattle management and wildliferelated risk factors. The potential impact of transmission from badgers to cattle has been estimated from the RBCT at $\sim 33 \%$ [227] although identification of the most important routes of transmission remains unresolved, thus hampering the development of targeted control measures.

In GB, mathematical modelling supports other work showing cattle movements, re-infection from wildlife and the performance of the main diagnostic test have a substantial influence on infection incidence [286]. Currently approved diagnostic tests for bTB are known to be variable in their performance and have only moderate sensitivity [135]. Significant improvements in diagnostic test accuracy and hence casedefinition could improve the estimation of the impact of risk factors, transmission rates and hence the development of appropriate control strategies. It has been estimated through modelling that up to $24 \%$ of British herds had residual infection in at least one animal when restrictions were lifted [76]. This is congruent with estimates from a descriptive analysis in Spain, where $22 \%$ of incidents were determined to have been caused by residual cattle infection [287]. There is evidence that the TST is influenced in the presence of Johne's disease [29] and liver fluke [63, 162] but the extent to which this might impede diagnosis is unknown. Potential impacts could be significant as the herd-level seroprevalence of Johne's disease in South-West England is high [288]. The geographical distributions of liver fluke and bTB infections are negatively correlated in England and Wales and it has been suggested that this is a result of masking of infection [289]. However the highest prevalence areas for liver fluke, such as Cumbria in Northern England [290] are not associated with higher than average detection of bTB infection by meat inspection, and bTB incidence remains low [84].

Accumulating evidence suggests that the susceptibility of cattle to $M$. bovis infection can be affected by breed and genotype but further work is required. About $20 \%$ of variation in resistance to bTB in British and Irish dairy cattle can be attributed to sire lineage, and there is evidence of similar variation in 
resistance in beef breeds. However, these may be under-estimates of heritability because of misclassification of estimated exposure to infection and imperfect diagnostic tests [291]. This approach of breeding resistance is being taken forward by the dairy industry in GB [292].

The risk from within farm movements of animals and herds, although hypothesised, has thus far not been investigated. It is rare for this data to be captured centrally and so investigation would require a bespoke study.

The identification of tractable risk factors for bTB is critical to a better understanding of infection dynamics and the development of cost-effective approaches to disease control. While a cattle farmer can alter their behaviour or farm management strategies including purchasing choices, it is less likely or more challenging to exert substantial control over extrinsic factors related to the environment or wildlife, or the level of infection in the surrounding area. In recognition of this there is a need to account for farmer behaviour and the drivers of their decisions in the development of infection control strategies [293, 294]. Few studies have related farmer perceptions to bTB incidence, and those that have shown conflicting results [115, 117, 295].

Knowledge of the importance of risk factors could be deployed to facilitate integrated control in two ways. First, certain risk factors may be shared among a range of pathogens of cattle although disease control in livestock usually focusses on individual infections. The identification of common risk factors should be used to develop more efficient, cost-effective holistic infection control programs. The identification of shared risk factors for brucellosis and bTB has indicated that such an approach is possible [117]. Second, the combination of country- and region-specific risk factors could be used to focus on multiple transmission pathways simultaneously to continuously improve a more effective, integrated and evidence-based control strategy. Such an approach would need to be carefully validated and its effects would need to be measured.

If $R_{0}$ is just $>1$, changes in factors with a moderate effect on transmission will have a big impact [296]. Modelling approaches suggest that focusing on a single route of transmission will not reverse the increasing trend in incidence [286]. This suggests a tailored package of control measures, addressing many transmission pathways, made possible by the identification of relevant risk factors is likely to be the most effective approach to bTB control in cattle.

\section{SUPPLEMENTARY MATERIAL}

For supplementary material accompanying this paper visit http://dx.doi.org/10.1017/S095026881600131X.

\section{ACKNOWLEDGEMENTS}

This review was funded by the UK Department for Environment, Food and Rural Affairs (Defra) under project SB4500. The authors thank Professor Dirk Pfeiffer (RVC), Drs Simon Rolfe (Welsh Government), Martyn Blissitt (Scottish Government) Ricardo de la Rua Domenech, Malla Hovi and James McCormack (Defra, UK), and Ms. Kate Harris (APHA, UK), who read and made comments on drafts at various stages. Thanks to Dr Gareth Enticott, Cardiff University, for comments regarding social risk factors, and to Liz Pritchard, Cameron Smith, Andrew Petit (APHA Library), and Mary O'Mara (APHA) for administrative support.

\section{DECLARATION OF INTEREST}

None.

\section{REFERENCES}

1. O'Reilly LM, Daborn CJ. The epidemiology of Mycobacterium bovis infections in animals and mana review. Tubercle and Lung Disease 1995; 76: 1-46.

2. Palmer MV. Mycobacterium bovis: Characteristics of Wildlife reservoir hosts. Transboundary and Emerging Diseases 2013; 60 (Suppl. 1): 1-13.

3. Abernethy DA, et al. Bovine tuberculosis trends in the UK and the Republic of Ireland, 1995-2010. Veterinary Record 2013; 172: 312.

4. Cosivi O, et al. Epidemiology of Mycobacterium bovis infection in animals and humans, with particular reference to Africa. Revue Scientifique et Technique. 1995; 14: 733-746.

5. Cousins DV, Roberts JL. Australia's campaign to eradicate bovine tuberculosis: the battle for freedom and beyond. Tuberculosis (Edinburgh) 2001; 81: 5-15.

6. Ramirez-Villaescusa AM, et al. Risk factors for herd breakdown with bovine tuberculosis in 148 cattle herds in the south west of England. Preventive Veterinary Medicine 2010; 95: 224-30.

7. Allepuz A, et al. Analysis of the spatial variation of Bovine tuberculosis disease risk in Spain (2006-2009). Preventive Veterinary Medicine 2011; 100: 44-52.

8. Thrusfield MV. Veterinary Epidemiology, 3rd edn. Wiley-Blackwell, 2007.

9. Coad M, et al. Repeat tuberculin skin testing leads to desensitisation in naturally infected tuberculous cattle which is associated with elevated interleukin-10 and 
decreased interleukin-1 beta responses. Veterinary Research 2010; 41: 14.

10. Thom ML, et al. The effect of tuberculin testing on the development of cell-mediated immune responses during mycobacterium bovis infection. Veterinary Immunology and Immunopathology 2006; 114: 25-36.

11. Brotherstone S, et al. Evidence of genetic resistance of cattle to infection with Mycobacterium bovis. Journal of Dairy Science 2010; 93: 1234-1242.

12. Bermingham ML, et al. Genetics of tuberculosis in Irish Holstein-Friesian dairy herds. Journal of Dairy Science 2009; 92: 3447-3456.

13. Bermingham ML, et al. Evidence for genetic variance in resistance to tuberculosis in Great Britain and Irish Holstein-Friesian populations. BMC Proceedings 2011; 5 (Suppl. 4): S15.

14. Richardson IW, et al. Variance components for susceptibility to Mycobacterium bovis infection in dairy and beef cattle. Genetics Selection Evolution 2014; 46.

15. Allen AR, et al. Bovine tuberculosis: the genetic basis of host susceptibility. Proceedings of the Royal Society of London, Series B: Biological Sciences 2010; 277: 27372745.

16. Morris CA. A review of genetic resistance to disease in Bos taurus cattle. Veterinary Journal 2007; 174: 481-491.

17. Driscoll EE, et al. A preliminary study of genetic factors that influence susceptibility to bovine tuberculosis in the British cattle herd. PLOS ONE 2011; 6.

18. Bermingham ML, et al. Genome-wide association study identifies novel loci associated with resistance to bovine tuberculosis. Heredity (Edinburgh) 2014; 112: 543-551.

19. Song Y, et al. Toll-like receptor 6 gene polymorphisms increase the risk of bovine tuberculosis in Chinese Holstein cattle. Acta histochemica 2014; 116: 1159-1162.

20. Butler ST. Genetic control of reproduction in dairy cows. Reproduction, Fertility and Development 2013; 26: $1-11$.

21. Bermingham ML, et al. Genetic correlations between measures of Mycobacterium bovis infection and economically important traits in Irish Holstein-Friesian dairy cows. Journal of Dairy Science 2010; 93: 5413-5422.

22. Vordermeier M, et al. The influence of cattle breed on susceptibility to bovine tuberculosis in Ethiopia. Comparative Immunology, Microbiology \& Infectious Diseases 2012; 35: 227-232.

23. Cadmus SIB, et al. Risk factors associated with bovine tuberculosis in some selected herds in Nigeria. Tropical Animal Health and Production 2010; 42: 547-549.

24. Ameni G, Amenu K, Tibbo M. Bovine tuberculosis: prevalence and risk factor assessment in cattle and cattle owners in Wuchale-Jida District, Central Ethiopia. International Journal of Applied Research in Veterinary Medicine 2003; 1: 17-26.

25. Dinka H, Duressa A. Prevalence of bovine tuberculosis in Arsi Zones of Oromia, Ethiopia. African Journal of Agricultural Research 2011; 6: 3858.

26. Ameni G, Erkihun A. Bovine tuberculosis an small-scale dairy farms in Adama Town, central Ethiopia, and farmer awareness of the disease. Revue Scientifique et Technique -Office International des Epizooties 2007; 26: 711-719.

27. Thakar A, et al. A study on the prevalence of bovine tuberculosis in farmed dairy cattle. Veterinary World 2010; 3: 409-413.

28. Bovine HapMap Consortium. Genome-wide survey of SNP vaiation uncovers the genetic structure of cattle breeds. Science 2009; 324: 528-532.

29. Alvarez J, et al. Effect of paratuberculosis on the diagnosis of bovine tuberculosis in a cattle herd with a mixed infection using interferon-gamma detection assay. Veterinary Microbiology 2009; 135: 389-393.

30. Bell M, et al. Risk factors for culling in Holstein-Friesian dairy cows. Veterinary Record 2010; 167: 238-240.

31. Brooks-Pollock E, et al. Age-dependent patterns of bovine tuberculosis in cattle. Veterinary Research 2013; 44.

32. Bonsu OA, Laing E, Akanmori BD. Prevalence of tuberculosis in cattle in the Dangme-West district of Ghana, public health implications. Acta Tropica 2000; 76: 9-14.

33. Teklu A, et al. Tuberculous lesions not detected by routine abattoir inspection: the experience of the Hossana municipal abattoir, southern Ethiopia. Revue Scientifique et Technique - Office International des Epizooties. 2004; 23: 957-964.

34. Singh BB, et al. Prevalence of bovine tuberculosis and paratuberculosis in Punjab. Indian Veterinary Journal 2004; 81: 1195-1196.

35. Fikru R, Bonnet $\mathbf{P}$, Moges W. Prevalence of bovine tuberculosis in indigenous Zebu cattle under extensive farming system in Western Ethiopia. Bulletin of Animal Health and Production in Africa 2005; 53: 85-88.

36. Inangolet FO, et al. A cross-sectional study of bovine tuberculosis in the transhumant and agro-pastoral cattle herds in the border areas of Katakwi and Moroto districts, Uganda. Tropical Animal Health and Production 2008; 40: 501-508.

37. Yacob HT, Basu A K, Guesh N. Bovine pulmonary tuberculosis at Bahir Dar municipality abattoir, Ethiopia. Bulletin of Animal Health and Production in Africa 2008; 56: 223-229.

38. Kazwala RR, et al. Risk factors associated with the occurrence of bovine tuberculosis in cattle in the Southern Highlands of Tanzania. Veterinary Research Communications. 2001; 25: 609-614.

39. Wood PR, Jones SL. BOVIGAM: an in vitro cellular diagnostic test for bovine tuberculosis. Tuberculosis (Edinburgh) 2001; 81: 147-155.

40. Rahman MA, Samad MA. Prevalence of bovine tuberculosis and its effects on milk production in Red Chittagong cattle. Bangladesh Journal of Veterinary Medicine 2008; 6: 175-178.

41. Garro C, et al. Tuberculosis in calves: results of a prospective study. Redvet 2011; 12: 121108.

42. Menzies FD, et al. A matched cohort study investigating the risk of Mycobacterium bovis infection in the progeny of infected cows. Veterinary Journal 2012; 194: 299-302.

43. Bernard F, et al. Tuberculosis and brucellosis prevalence survey on dairy cattle in Mbarara milk basin (Uganda). Preventive Veterinary Medicine 2005; 67: 267-281. 
44. Gumi B, et al. Prevalence of bovine tuberculosis in pastoral cattle herds in the Oromia region, southern Ethiopia. Tropical Animal Health and Production. 2011; 43: 1081-1087.

45. Gezahegne M, et al. Bovine tuberculosis and its associated risk factors in pastoral and agro-pastoral cattle herds of Afar Region, Northeast Ethiopia. Journal of Veterinary Medicine and Animal Health 2013; 5: 171-179.

46. Gormley E, et al. Identification of risk factors associated with disclosure of false positive bovine tuberculosis reactors using the gamma-interferon (IFN gamma) assay. Veterinary Research 2013; 44.

47. Biratu N, et al. Epidemiology of bovine tuberculosis in Butajira, Southern Ethiopia: a cross-sectional abattoirbased study. African Journal of Microbiology Research 2014; 8: 3112-3117.

48. Moiane I, et al. Prevalence of bovine tuberculosis and risk factor assessment in cattle in rural livestock areas of Govuro district in the southeast of Mozambique. PLOS ONE 2014; 9: e91527.

49. Wolfe DM, et al. The risk of a positive test for bovine tuberculosis in cattle purchased from herds with and without a recent history of bovine tuberculosis in Ireland. Preventive Veterinary Medicine 2009; 92: 99-105.

50. Humblet MF, Boschiroli ML, Saegerman C. Classification of worldwide bovine tuberculosis risk factors in cattle: a stratified approach. Veterinary Research 2009; 40: 50 .

51. Pollock JM, Neill SD. Mycobacterium bovis infection and tuberculosis in cattle. Veterinary Journal 2002; 163: $115-127$.

52. Field CJ, Johnson IR. Nutrients and their role in host resistance to infection. Journal of Leukocyte Biology 2002; 71: 16-32.

53. Schaible UE, Kaufmann SH. Malnutrition and infection: complex mechanisms and global impacts. PLoS Medicine 2007; 4: e115.

54. van Crevel R, et al. Decreased plasma leptin concentrations in tuberculosis patients are associated with wasting and inflammation. Journal of Clinical Endocrinology and Metabolism 2002; 87: 758-763.

55. Downs SH, et al. Trace micro-nutrients may affect susceptibility to bovine tuberculosis in cattle. Preventive Veterinary Medicine 2008; 87: 311-326.

56. Doherty ML, et al. Effect of dietary restriction on cellmediated immune responses in cattle infected with Mycobacterium bovis. Veterinary Immunology and Immunopathology 1996; 49: 307-320.

57. Costello E, et al. A study of cattle-to-cattle transmission of Mycobacterium bovis infection. Veterinary Journal 1998; 155: 245-250.

58. White PCL, et al. Control of bovine tuberculosis in British livestock: there is no 'silver bullet'. Trends in Microbiology 2008; 16: 420-427.

59. Sauter CM, Morris RS. Behavioural studies on the potential for direct transmission of tuberculosis from feral ferrets (Mustela furo) and possums (Trichosurus vulpecula) to farmed livestock. New Zealand Veterinary Journal 1995; 43: 294-300.
60. MacKay PC, Wood-Gush DCM. Exploration and fear in calves newly turned out to pasture. Applied Animal Behavioural Science 1985; 14: 392-393.

61. Bohm M, Hutchings MR, White PC. Contact networks in a wildlife-livestock host community: identifying highrisk individuals in the transmission of bovine TB among badgers and cattle. PLoS ONE 2009; 4: e5016.

62. Sauter CM, Morris RS. Dominance hierarchies in cattle and red deer (Cervus elaphus): their possible relationship to the transmission of bovine tuberculosis. New Zealand Veterinary Journal 1995; 43: 301-305.

63. Flynn RJ, et al. Co-infection of cattle with Fasciola hepatica and Mycobacterium bovis - immunological consequences. Transboundary and Emerging Diseases 2009; 56: 269-274.

64. Jolles AE, et al. Interactions between macroparasites and microparasites drive infection patterns in freeranging African buffalo. Ecology 2008; 89: 2239-2250.

65. Ezenwa VO, et al. Hidden consequences of living in a wormy world: nematode-induced immune suppression facilitates tuberculosis invasion in African buffalo. American Naturalist 2010; 176: 613-624.

66. de la Rua-Domenech $\mathbf{R}$, et al. Ante mortem diagnosis of tuberculosis in cattle: a review of the tuberculin tests, gamma-interferon assay and other ancillary diagnostic techniques. Research in Veterinary Science 2006; 81: 190-210.

67. Morrison W, et al. Pathogenesis and diagnosis of infections with Mycobacterium bovis in cattlte. Independant Scientific Group on Cattle TB. Veterinary Record 2000; 146: $236-242$.

68. Watson CW. An investigation into the possible relationships between BVD and TB in practice. Cattle Practice 2002; 10: 101-103.

69. Kao RR, et al. Mycobacterium bovis shedding patterns from experimentally infected calves and the effect of concurrent infection with bovine viral diarrhoea virus. Journal of the Royal Society Interface 2007; 4: 545-551.

70. Johnston WT, et al. Herd-level risk factors of bovine tuberculosis in England and Wales after the 2001 foot-and-mouth disease epidemic. International Journal of Infectious Diseases 2011; 15: e833-e40.

71. Johnston WT, et al. Herd-level risk factors associated with tuberculosis breakdowns among cattle herds in England before the 2001 foot-and-mouth disease epidemic. Biology Letters 2005; 1: 53-56.

72. Godfray HCJ, et al. A restatement of the natural science evidence base relevant to the control of bovine tuberculosis in Great Britain. Proceedings of the Royal Society of London, Series B: Biological Sciences 2013; 280: 20131634.

73. Skuce RA, Allen AR, McDowell SW. Herd-level risk factors for bovine tuberculosis: a literature review. Veterinary Medicine International 2012; 2012: 621210.

74. More SJ, Good M. Understanding and managing bTB risk: perspectives from Ireland. Veterinary Microbiology 2015; 176: $209-218$.

75. Vial F, et al. Bovine tuberculosis risk factors for British herds before and after the 2001 foot-and-mouth epidemic: what have we learned from the TB99 and CCS2005 
studies? Transboundary and Emerging Diseases 2015; 62: 505-515.

76. Conlan AJ, et al. Estimating the hidden burden of bovine tuberculosis in Great Britain. PLoS Computational Biology 2012; 8: e1002730.

77. Omer MK, et al. A cross-sectional study of bovine tuberculosis in dairy farms in Asmara, Eritrea. Tropical Animal Health and Production 2001; 33: 295-303.

78. Marangon S, et al. A case-control study on bovine tuberculosis in the Veneto Region (Italy). Preventive Veterinary Medicine 1998; 34: 87-95.

79. Garro C, et al. Risk factors for bovine tuberculosis in dairy herds in Cordoba and Santa $\mathrm{Fe}$ provinces. Revista Argentina de Produccion Animal 2010; 30: 167-178.

80. Goodchild AV, Clifton-Hadley RS. Cattle-to-cattle transmission of Mycobacterium bovis. Tuberculosis 2001; 81: 23-41.

81. O'Mahony DT. Badger-cattle interactions in the rural environment: Implications for bovine tuberculosis transmission. Northern Ireland, 2014.

82. Doyle LP, et al. Bovine tuberculosis in Northern Ireland: risk factors associated with time from postoutbreak test to subsequent herd breakdown. Preventive Veterinary Medicine 2014; 116: 47-55.

83. Gallagher MJ, et al. Comparison of bovine tuberculosis recurrence in Irish herds between 1998 and 2008. Preventive Veterinary Medicine 2013; 111: 237-244.

84. APHA. Bovine tuberculosis: Infection status in cattle in England: Annual surveillance report for the period January to December 2014. 2015.

85. Alvarez $\mathbf{J}$, et al. Risk factors associated with negative in-vivo diagnostic results in bovine tuberculosis-infected cattle in Spain. BMC Veterinary Research 2014; 10.

86. O'Hagan MJ, et al. Risk factors for visible lesions or positive laboratory tests in bovine tuberculosis reactor cattle in Northern Ireland. Preventive Veterinary Medicine 2015; 120: 283-290.

87. Downs SH, et al. Differences in the response to diagnostic tests for bovine tuberculosis between dairy cattle and non-dairy cattle naturally exposed to Mycobacterium bovis in Great Britain. Veterinary Journal. Accepted. doi:10.1016/j.tvj1.2016.06.010.

88. Griffin JM, et al. A case-control study on the association of selected risk factors with the occurrence of bovine tuberculosis in the Republic of Ireland. Preventive Veterinary Medicine 1996; 27: 75-87.

89. Denny GO, Wilesmith JW. Bovine tuberculosis in Northern Ireland: a case-control study of herd risk factors. Veterinary Record 1999; 144: 305-310.

90. Mill AC, et al. Farm-scale risk factors for bovine tuberculosis incidence in cattle herds during the Randomized Badger Culling Trial. Epidemiology and Infection 2012; 140: $219-30$.

91. Vial F, Johnston WT, Donnelly CA. Local cattle and badger populations affect the risk of confirmed tuberculosis in British cattle herds. PLoS ONE 2011 6: e18058.

92. Guta S, et al. Risk factors for bovine tuberculosis persistence in beef herds of southern and central Spain. Preventive Veterinary Medicine 2014; 115: 173-180.
93. Reilly LA, Courtenay O. Husbandry practices, badger sett density and habitat composition as risk factors for transient and persistent bovine tuberculosis on UK cattle farms. Preventive Veterinary Medicine 2007; 80: 129-142.

94. Griffin JM, Dolan LA. The role of cattle-to-cattle transmission of Mycobacterium bovis in the epidemiology of tuberculosis in cattle in the Republic of Ireland - a review. Irish Veterinary Journal 1995; 48: 228-234.

95. Griffin JM, et al. The association of cattle husbandry practices, environmental factors and farmer characteristics with the occurrence of chronic bovine tuberculosis in dairy herds in the Republic of Ireland. Preventive Veterinary Medicine 1993; 17: 145-160.

96. White PW, et al. The importance of 'neighbourhood' in the persistence of bovine tuberculosis in Irish cattle herds. Preventive Veterinary Medicine 2013; 110: 346-355.

97. Carrique-Mas JJ, Medley GF, Green LE. Risks for bovine tuberculosis in British cattle farms restocked after the foot and mouth disease epidemic of 2001. Preventive Veterinary Medicine 2008; 84: 85-93.

98. Ramirez-Villaescusa AM, et al. Herd and individual animal risks associated with bovine tuberculosis skin test positivity in cattle in herds in south west England. Preventive Veterinary Medicine 2009; 92: 188-198.

99. Gilbert M, et al. Cattle movements and bovine tuberculosis in Great Britain. Nature (London) 2005; 435: 491-496.

100. White PCL, Benhin JKA. Factors influencing the incidence and scale of bovine tuberculosis in cattle in southwest England. Preventive Veterinary Medicine 2004; 63: $1-7$.

101. Ward AI, Tolhurst BA, Delahay RJ. Farm husbandry and the risks of disease transmission between wild and domestic mammals: a brief review focusing on bovine tuberculosis in badgers and cattle. Animal Science 2006; 82: 767-773.

102. Gopal R, et al. Introduction of bovine tuberculosis to north-east England by bought-in cattle. Veterinary Record 2006; 159: 265-271.

103. Humblet MF, et al. New assessment of bovine tuberculosis risk factors in Belgium based on nationwide molecular epidemiology. Journal of Clinical Microbiology 2010; 48: 2802-2808.

104. Clegg TA, et al. Potential infection-control benefit for Ireland from pre-movement testing of cattle for tuberculosis. Preventive Veterinary Medicine 2008; 84: 94-111.

105. Griffin JM. The role of bought-in cattle in herd breakdowns due to tuberculosis in part of County Cavan during 1989. Irish Veterinary Journal 1993; 46: 143-148.

106. Gates MC, Volkova VV, Woolhouse MEJ. Risk factors for bovine tuberculosis in low incidence regions related to the movements of cattle. BMC Veterinary Research 2013; 9(225).

107. Abernethy DA, Pfeiffer DU, Neill SD (eds). Case control study examining the role of livestock markets in the transmission of bovine tuberculosis. Proceedings of Society for Veterinary Epidemiology and Preventive Medicine, 2000. University of Edinburgh. 
108. Steger G. Bovine tuberculosis at cattle shows. Tierarzliche Umschau 1970; 22: 416-421.

109. Elias K, et al. Status of bovine tuberculosis in Addis Ababa dairy farms. Revue Scientifique et Technique Office International des Epizooties 2008; 27: 915-923.

110. Asseged B, et al. Bovine tuberculosis: a cross sectional and epidemiological study in and around Addis Ababa. Bulletin of Animal Health and Production in Africa 2000; 48: 71-80.

111. Regassa A, et al. A cross-sectional study on bovine tuberculosis in Hawassa town and its surroundings, Southern Ethiopia. Tropical Animal Health and Production 2010; 42: 915-920.

112. Munyeme M, et al. Risk factors associated with bovine tuberculosis in traditional cattle of the livestock/wildlife interface areas in the Kafue basin of Zambia. Preventive Veterinary Medicine 2008; 85: 317-328.

113. Khan IA, Khan A. Prevalence and risk factors of bovine tuberculosis in Nili Ravi buffaloes in the Punjab, Pakistan. Italian Journal of Animal Science 2007; 6: 817-820.

114. Christiansen KH, Clifton-Hadley RS. Farm management risk factors for bovine tuberculosis. Veterinary Laboratories Agency, Addlestone. Surrey, UK: Report to the Milk Development Council, 2000.

115. Cowie CE, et al. Risk factors for the detected presence of Mycobacterium bovis in cattle in south central Spain. European Journal of Wildlife Research 2014; 60: 113-123.

116. Winkler B, Mathews F. Environmental risk factors associated with bovine tuberculosis among cattle in high-risk areas. Biology Letters 2015; 11.

117. Cowie CE, et al. Shared risk factors for multiple livestock diseases: a case study of bovine tuberculosis and brucellosis. Research in Veterinary Science 2014; 97: 491-497.

118. Lanszki J, et al. Feeding habits and trophic niche overlap in a Carnivora community of Hungary. Acta Theriologica 1999; 44: 429-442.

119. Garnett BT, Delahay RJ, Roper TJ. Use of cattle farm resources by badgers (Meles meles) and risk of bovine tuberculosis (Mycobacterium bovis) transmission to cattle. Proceedings of the Royal Society of London, Series B: Biological Sciences 2002; 269: 1487-1491.

120. Defra. An experiment to assess the cost-effectiveness of farm husbandry manipulations to reduce risks associated with farmyard contact between badgers and cattle. London: 2010.

121. Griffin JM, Hahesy T. Analysis of epidemiology reports on 3975 herd breakdowns in ten DVO regions during 1987-90. Irish Veterinary Journal 1992; 45: 126.

122. Broughan JM, et al. Mycobacterium bovis infections in domesticated non-bovine mammalian species. Part 1: Review of epidemiology and laboratory submissions in Great Britain 2004-2010. Veterinary Journal 2013; 198: $339-345$.

123. Karolemeas K, et al. Predicting prolonged bovine tuberculosis breakdowns in Great Britain as an aid to control. Preventive Veterinary Medicine 2010; 97: 183-190.
124. Karolemeas K, et al. Recurrence of bovine tuberculosis breakdowns in Great Britain: risk factors and prediction. Preventive Veterinary Medicine 2011; 102: 22-29.

125. Olea-Popelka FJ, et al. Breakdown severity during a bovine tuberculosis episode as a predictor of future herd breakdowns in Ireland. Preventive Veterinary Medicine 2004; 63: 163-172.

126. Abernethy DA, et al. Shifting the TB-control paradigm: an epidemiological critique of the bovine tuberculosis eradication scheme. Alban L, Kelly LA, eds, 2010, pp. 166-173.

127. Dawson KL, et al. Recurrent bovine tuberculosis in New Zealand cattle and deer herds, 2006-2010. Epidemiology and Infection 2014; 142: 2065-2074.

128. Green L, Medley G. Cattle to cattle transmission of bovine tuberculosis: risk factors and dynamics. Cattle Practice 2008; 16: 116-121.

129. Good M, et al. Impact of the national full herd depopulation policy on the recurrence of bovine tuberculosis in Irish herds, 2003 to 2005. Veterinary Record 2011; 169: 581.

130. Wolfe DM, et al. From explanation to prediction: A model for recurrent bovine tuberculosis in Irish cattle herds. Preventive Veterinary Medicine 2010; 94: 170-177.

131. Green LE, et al. Patterns of delayed detection and persistence of bovine tuberculosis in confirmed and unconfirmed herd breakdowns in cattle and cattle herds in Great Britain. Preventive Veterinary Medicine 2012; 106: 266-274.

132. Berrian AM, et al. Risk of bovine tuberculosis for cattle sold out from herds during 2005 in Ireland. Veterinary Record 2012; 170: 620.

133. Clegg TA, et al. Shorter-term risk of Mycobacterium bovis in Irish cattle following an inconclusive diagnosis to the single intradermal comparative tuberculin test. Preventive Veterinary Medicine 2011; 102: 255-264.

134. Clegg TA, et al. Longer-term risk of Mycobacterium bovis in Irish cattle following an inconclusive diagnosis to the single intradermal comparative tuberculin test. Preventive Veterinary Medicine 2011; 100: 147-154.

135. EFSA. EFSA Panel on Animal Health and Welfare (AHAW); Scientific Opinion on the use of a gamma interferon test for the diagnosis of bovine tuberculosis EFSA Journal 2012; 10: 2975

136. Monaghan ML, et al. The tuberculin test. Cattle Practice 2005; 13: 337-345.

137. Schiller I, et al. Comparison of tuberculin activity using the interferon-gamma assay for the diagnosis of bovine tuberculosis. Veterinary Record 2010; 167: 322-326.

138. Downs SH, et al. Tuberculin manufacturing source and breakdown incidence rate of bovine tuberculosis in British cattle, 2005-2009. Veterinary Record 2013; 172: 98 .

139. Ngandolo BNR, et al. Comparative assessment of fluorescence polarization and tuberculin skin testing for the diagnosis of bovine tuberculosis in Chadian cattle. Preventive Veterinary Medicine 2009; 89: $81-89$. 
140. Meskell P, Devitt C, More SJ. Challenges to quality testing for bovine tuberculosis in Ireland; perspectives from major stakeholders. Veterinary Record 2013; 173: 94.

141. Humblet MF, et al. Monitoring of the intra-dermal tuberculosis skin test performed by Belgian field practitioners. Research in Veterinary Science 2011; 91: 199-207.

142. Gormley E, et al. Diagnosis of Mycobacterium bovis infection in cattle by use of the gamma-interferon (Bovigam) assay. Veterinary Microbiology 2006; 112: 171-179.

143. Shitaye JE, Tsegaye W, Pavlik I. Bovine tuberculosis infection in animal and human populations in Ethiopia: a review. Veterinarni Medicina 2007; 52: 317-332.

144. Monaghan ML, et al. Sensitisation of cattle to bovine and avian tuberculins with Mycobacterium cookii. Veterinary Record 1991; 129: 383.

145. Kerr WR, Lamont HG, McGirr JL. Studies on tuberculin sensitivity in the bovine. Veterinary Record 1946; 58: 443-453.

146. Ryan TJ, Buddle BM, De Lisle GW. An evaluation of the gamma interferon test for detecting bovine tuberculosis in cattle 8 to 28 days after tuberculin skin testing. Research in Veterinary Science 2000; 69: 57-61.

147. Rangen SA, et al. Is the gamma interferon assay in cattle influenced by multiple tuberculin injections? Canadian Veterinary Journal/Revue Veterinaire Canadienne. 2009; 50: 270-274.

148. Huitema H. The eradication of bovine tuberculosis in cattle in the Netherlands and the significance of man as a source of infection for cattle. Selected Papers of the Royal Netherlands Tuberculosis Association 1969; 12: $62-67$.

149. Buddle BM, et al. Experimental Mycobacterium bovis infection of cattle: effect of dose of $\mathrm{M}$. bovis and pregnancy on immune responses and distribution of lesions. New Zealand Veterinary Journal 1994: $167-172$.

150. Amos W, et al. Genetic predisposition to pass the standard SICCT test for bovine tuberculosis in British cattle. PLOS ONE 2013; 8: e58245.

151. Wright DM, et al. Detectability of bovine TB using the tuberculin skin test does not vary significantly according to pathogen genotype within Northern Ireland. Infection, Genetics and Evolution 2013; 19: 15-22.

152. Amadori M, et al. Diagnosis of Mycobacterium bovis infection in calves sensitized by mycobacteria of the avium/intracellulare group. Journal of Veterinary Medicine, Series B: Infectious Diseases and Veterinary Public Health 2002; 49: 89-96.

153. Hope JC, et al. Exposure to Mycobacterium avium induces low-level protection from Mycobacterium bovis infection but compromises diagnosis of disease in cattle. Clinical and Experimental Immunology 2005; 141: 432-439.

154. Barry C, et al. The effect of Mycobacterium avium complex infections on routine Mycobacterium bovis diagnostic tests. Veterinary Medicine International 2011; 2011: 145092.
155. Michel AL. Mycobacterium fortuitum infection interference with Mycobacterium bovis diagnostics: natural infection cases and a pilot experimental infection. Journal of Veterinary Diagnostic Investigation 2008; 20: 501-503.

156. Waters WR, et al. Immune responses to defined antigens of Mycobacterium bovis in cattle experimentally infected with Mycobacterium kansasii. Clinical and Vaccine Immunology 2006; 13: 611-619.

157. Waters WR, et al. Immune responses in cattle inoculated with Mycobacterium bovis, Mycobacterium tuberculosis, or Mycobacterium kansasii. Clinical and Vaccine Immunology 2010; 17: 247-252.

158. Vordermeier HM, et al. Assessment of cross-re activity between Mycobacterium bovis and M. kansasii ESAT-6 and CFP-10 at the T-Cell epitope level. Clinical and Vaccine Immunology 2007; 14: 1203-1209.

159. Corner LA, Pearson CW. Response of cattle to inoculation with atypical mycobacteria isolated from soil. Australian Veterinary Journal 1979; 55: 6-9.

160. Thom M, et al. Consequence of prior exposure to environmental mycobacteria on $\mathrm{BCG}$ vaccination and diagnosis of tuberculosis infection. Tuberculosis 2008; 88: $324-334$.

161. Howard CJ, et al. Exposure to Mycobacterium avium primes the immune system of calves for vaccination with Mycobacterium bovis BCG. Clinical \& Experimental Immunology 2002; 130: 190-195.

162. Flynn RJ, et al. Experimental Fasciola hepatica infection alters responses to tests used for diagnosis of bovine tuberculosis. Infection and Immunity 2007; 75: 1373-1381.

163. Ameni G, Medhin G. Effect of gastro-intestinal parasitosis on tuberculin test for the diagnosis of bovine tuberculosis. Journal of Applied Animal Research 2000; 18: 221-224.

164. McDonald WL, et al. Evaluation of diagnostic tests for Johne's disease in young cattle. Australian Veterinary Journal 1999; 77: 113-119.

165. Marassi CD, et al. The use of MPB70 and MPB83 to distinguish between bovine tuberculosis and paratuberculosis. Comparative Immunology Microbiology and Infectious Diseases 2010; 33: 485-489.

166. Brito BP, et al. Association between caudal fold tuberculin test responses and results of an ELISA for Mycobacterium avium subsp. paratuberculosis and mycobacterial culture of feces in tuberculosis-free dairy herds. Journal of the American Veterinary Medical Association 2014; 244: 582-587.

167. Aranaz A, et al. Assessment of diagnostic tools for eradication of bovine tuberculosis in cattle co-infected with Mycobacterium bovis and M. avium subsp. paratuberculosis. Veterinary Research 2006; 37: 593-606.

168. Seva J, et al. Evaluation of the single cervical skin test and interferon gamma responses to detect Mycobacterium bovis infected cattle in a herd co-infected with Mycobacterium avium subsp paratuberculosis. Veterinary Microbiology 2014; 171: 139-146.

169. Muskens J, et al. Evaluation of the long-term immune response in cattle after vaccination against paratuberculosis 
in two Dutch dairy herds. Veterinary Microbiology. 2002; 86: 269-278.

170. Thomsen VT, et al. Characterization of the long-term immune response to vaccination against Mycobacterium avium subsp paratuberculosis in Danish dairy cows. Veterinary Immunology and Immunopathology 2012; 145: 316-322.

171. Kohler H, et al. Immune reactions in cattle after immunization with a Mycobacterium paratuberculosis vaccine and implications for the diagnosis of M. paratuberculosis and M. bovis infections. Journal of Veterinary Medicine, Series B: Infectious Diseases and Veterinary Public Health 2001; 48: 185-195.

172. Coad M, et al. The consequences of vaccination with the Johne's disease vaccine, Gudair, on diagnosis of bovine tuberculosis. Veterinary Record 2013; 172.

173. Garrido JM, et al. Paratuberculosis vaccination causes only limited cross-reactivity in the skin test for diagnosis of bovine tuberculosis. PLOS ONE 2013; 8.

174. Tewari D, et al. Mycobacterium avium subsp paratuberculosis antibody response, fecal shedding, and antibody cross-reactivity to Mycobacterium bovis in M. avium subsp paratuberculosis-infected cattle herds vaccinated against Johne's Disease. Clinical and Vaccine Immunology 2014; 21: 698-703.

175. Courtenay O, Wellington EMH. Mycobacterium bovis in the environment: towards our understanding of its biology. Cattle Practice 2008; 16: 122-126.

176. Williams RS, Hoy WA. The viability of B. tuberculosis (bovinus) on pasture land, in stored faeces and in liquid manure. Journal of Hygiene (London) 1930; 30: 413-419.

177. Jackson R, deLisle GW, Morris RS. A study of the environmental survival of Mycobacterium bovis on a farm in New Zealand. New Zealand Veterinary Journal 1995; 43: 346-352.

178. Fine AE, et al. A study of the persistence of Mycobacterium bovis in the environment under natural weather conditions in Michigan, USA. Veterinary Medicine International. 2011; 2011: Article ID 765430.

179. Duffield BJ, Young DA. Survival of Mycobacterium bovis in defined environmental conditions. Veterinary Microbiology 1985; 10: 193-197.

180. Vera A, Volkovsky G. Survival of Mycobacterium bovis in cattle faeces at different times of the year in Cuba. Revista Cubana de Ciencias Veterinarias. 1982; 13: $65-73$.

181. Barron MC, et al. Longevity of Mycobacterium bovis in brushtail possum (Trichosurus vulpecula) carcasses, and contact rates between possums and carcasses. New Zealand Veterinary Journal 2011; 59: 209-217.

182. Palmer MV, Whipple DL. Survival of Mycobacterium bovis on feedstuffs commonly used as supplemental feed for white-tailed deer (Odocoileus virginianus). Journal of Wildlife Diseases 2006; 42: 853-858.

183. Hahesy T, et al. Cattle manure and the spread of bovine tuberculosis. Irish Veterinary Journal 1992; 45: 122-123.

184. McCallan L, McNair J, Skuce R. A review of the potential role of cattle slurry in the spread of bovine tuberculosis. Agri-food and Biosciences Institute, Northern Ireland, 2014.

185. Scanlon MP, Quinn PJ. The survival of Mycobacterium bovis in sterilized cattle slurry and its relevance to the persistence of this pathogen in the environment. Irish Veterinary Journal 2000; 53: 412-415.

186. Gannon BW, Hayes CM, Roe JM. Survival rate of airborne Mycobacterium bovis. Research in Veterinary Science 2007; 82: 169-172.

187. Young JS, Gormley E, Wellington EM. Molecular detection of Mycobacterium bovis and Mycobacterium bovis BCG (Pasteur) in soil. Applied and Environmental Microbiology 2005; 71: 1946-1952.

188. Little TW, et al. Bovine tuberculosis in domestic and wild mammals in an area of Dorset. II. The badger population, its ecology and tuberculosis status. Journal of Hygiene (London) 1982; 89: 211-224.

189. Witmer G, et al. Epizootiologic survey of Mycobacterium bovis in wildlife and farm environments in northern Michigan. Journal of Wildlife Diseases 2010; 46: 368-378.

190. Fine AE, et al. An effort to isolate Mycobacterium bovis from environmental substrates during investigations of bovine tuberculosis transmission sites (cattle farms and wildlife areas) in Michigan, USA. ISRN Veterinary Science 2011; 2011: Article ID 787181.

191. Pillai SD, et al. Failure to identify non-bovine reservoirs of Mycobacterium bovis in a region with a history of infected dairy-cattle herds. Preventive Veterinary Medicine 2000; 43: 53-62.

192. O'Brien DJ, et al. Managing the wildlife reservoir of Mycobacterium bovis: the Michigan, USA, experience. Veterinary Microbiology 2006; 112: 313-323.

193. Jenkins HE, Woodroffe R, Donnelly CA. The effects of annual widespread badger culls on cattle tuberculosis following the cessation of culling. International Journal of Infectious Diseases 2008; 12: 457-465.

194. Goodchild AV, et al. Geographical association between the genotype of bovine tuberculosis in found dead badgers and in cattle herds. Veterinary Record 2012; 170: 259.

195. Murphy D, et al. The prevalence and distribution of Mycobacterium bovis infection in European badgers (Meles meles) as determined by enhanced post mortem examination and bacteriological culture. Research in Veterinary Science 2010; 88: 1-5.

196. Sweeney FP, et al. Environmental monitoring of Mycobacterium bovis in badger feces and badger sett soil by real-time PCR, as confirmed by immunofluorescence, immunocapture, and cultivation. Applied and Environmental Microbiology 2007; 73: 7471-7473.

197. Parsons LM, et al. Rapid and simple approach for identification of Mycobacterium tuberculosis complex isolates by PCR-based genomic deletion analysis. Journal of Clinical Microbiology 2002; 40: 2339-2345.

198. Wint GRW, et al. Mapping bovine tuberculosis in Great Britain using environmental data. Trends in Microbiology 2002; 10: 441-444.

199. Hahesy T, Kelleher D L, Doherty J. An investigation of a possible association between the occurrence of 
bovine tuberculosis and weather variables. Irish Veterinary Journal 1992; 45: 127-128.

200. Woodroffe R, et al. Culling and cattle controls influence tuberculosis risk for badgers. Proceedings of the National Academy of Sciences USA 2006; 103: 14713-14717.

201. Hancox M. Bovine TB and drought. Veterinary Record 1988; 122: 214

202. Cleaveland S, et al. Mycobacterium bovis in rural Tanzania: risk factors for infection in human and cattle populations. Tuberculosis 2007; 87: 30-43.

203. Balako G, et al. Prevalence of bovine tuberculosis in pastoral cattle herds in the Oromia region, southern Ethiopia. Tropical Animal Health and Production 2011; 43: 1081-1087.

204. Tadeusz H, Bouazza K. Control of bovine tuberculosis in the Kenitra district, Morocco; results, reflections and suggestions. Maghreb Veterinaire 1984; 1: 13-16.

205. Mathews F, et al. Bovine tuberculosis in cattle: reduced risk on wildlife-friendly farms. Biology Letters 2006; 2: 271-274.

206. Menzies FD, et al. A comparison of badger activity in two areas of high and low bovine tuberculosis incidence of Northern Ireland. Veterinary Microbiology 2011; 151: 112-119.

207. Kaneene JB, et al. Environmental and farm management factors associated with tuberculosis on cattle farms in northeastern Michigan. Journal of the American Veterinary Medical Association 2002; 221: 837-842.

208. Kelly GE, More SJ. Spatial clustering of TB-infected cattle herds prior to and following proactive badger removal. Epidemiology and Infection 2011; 139: 1220-1229.

209. White PCL, Brown JA, Harris S. Badgers (Meles meles), cattle and bovine tuberculosis (Mycobacterium bovis): a hypothesis to explain the influence of habitat on the risk of disease transmission in southwest England. Proceedings of the Royal Society of London, Series B: Biological Sciences 1993; 253: 277-284.

210. Newton-Cross G, White PCL, Harris S. Modelling the distribution of badgers Meles meles: comparing predictions from field-based and remotely derived habitat data. Mammal Review 2007; 37: 54-70.

211. Neal E. The Natural History of Badgers. Beckenham, Kent: Croom Helm, 1986.

212. Hammond RF, McGrath G, Martin SW. Irish soil and land-use classifications as predictors of numbers of badgers and badger setts. Preventive Veterinary Medicine 2001; 51: 137-148.

213. Walter WD, et al. Linking bovine tuberculosis on cattle farms to white-tailed deer and environmental variables using Bayesian hierarchical analysis. PLoS ONE 2014; 9: e90925.

214. Delahay RJ, et al. Distribution of badger latrines in a high-density population: habitat selection and implications for the transmission of bovine tuberculosis to cattle. Journal of Zoology 2007; 272: 311-320.

215. Hutchings MR, Service KM, Harris S. Is population density correlated with faecal and urine scent marking in European badgers (Meles meles) in the UK? Mammalian Biology 2002; 67: 286-293.

216. Kazoora HB, et al. Prevalence of Mycobacterium bovis skin positivity and associated risk factors in cattle from Western Uganda. Tropical Animal Health and Production 2014; 46: 1383-1390.

217. Fischer OA, et al. Earthworms (Oligochaeta, Lumbricidae) and mycobacteria. Veterinary Microbiology 2003; 91: 325-338.

218. Wilson G, et al. Scientific review on Tuberculosis in wildlife in the EU. EFSA, 2009.

219. Blagodarnyi YA, et al. The role of ticks in the transmission of the mycobacteria of tuberculosis. Veterinariya 1971; 7: 48-49.

220. Torres L, et al. Identification of microorganisms in partially fed female horn flies, Haematobia irritans. Parasitology Research 2012; 111: 1391-1395.

221. Taylor SJ, et al. Infection of Acanthamoeba castellanii with Mycobacterium bovis and M-bovis BCG and survival of M-bovis within the amoebae. Applied and Environmental Microbiology 2003; 69: 4316-4319.

222. Mardare C, Delahay RJ, Dale JW. Environmental amoebae do not support the long-term survival of virulent mycobacteria. Journal of Applied Microbiology 2013; 114: 1388-1394.

223. Haydon DT, et al. Identifying reservoirs of infection: a conceptual and practical challenge. Emerging Infectious Diseases 2002 (http://www.cdc.gov/ncidod/ EID/vol8no12/01-0317.htm).

224. Donnelly CA, et al. Positive and negative effects of widespread badger culling on tuberculosis in cattle. Nature (London) 2006; 439: 843-846.

225. Donnelly CA, et al. Impact of localized badger culling on tuberculosis incidence in British cattle. Nature (London) 2003; 426: 834-837.

226. Griffin JM, et al. Tuberculosis in cattle: the results of the four-area project. Irish Veterinary Journal 2005; 58: 629-636.

227. Bourne J. Bovine TB: the scientific evidence a science base for a sustainable policy to control TB in cattle, an epidemiological investigation in bovine tuberculosis. 2007.

228. Smith GC, Cheeseman CL. TB policy and the ISG's findings. Veterinary Record 2007; 161: 535.

229. Donnelly CA, Nouvellet P. The contribution of badgers to confirmed tuberculosis in cattle in high-incidence areas in England. PLoS Currents 2013; 5.

230. Martin SW, et al. The association between the bovine tuberculosis status of herds in the East Offaly Project Area Irish Republic, and the distance to badger setts, 1988-1993. Preventive Veterinary Medicine 1997; 31: $113-125$.

231. Clifton-Hadley RS, Wilesmith JW, Stuart FA. Mycobacterium bovis in the European badger (Meles meles): epidemiological findings in tuberculous badgers from a naturally infected population. Epidemiology and Infection 1993; 111: 9-19.

232. Courtenay O, et al. Is Mycobacterium bovis in the environment important for the persistence of bovine tuberculosis? Biology Letters 2006; 2: 460-462. 
233. Wilesmith JW, et al. Tuberculosis in East Sussex. I. Outbreaks of tuberculosis in cattle herds (1964-1984). Journal of Hygiene 1986; 97: 1-10.

234. Phillips CJC, et al. The transmission of Mycobacterium bovis infection to cattle. Research in Veterinary Science 2003; 74: 1-15.

235. Benham PF, Broom DM. Interactions between cattle and badgers at pasture with reference to bovine tuberculosis transmission. British Veterinary Journal 1989; 145: 226-241.

236. Mullen EM, et al. Foraging Eurasian badgers Meles meles and the presence of cattle in pastures. Do badgers avoid cattle? Applied Animal Behaviour Science 2013; 144: 130-137.

237. Drewe JA, et al. Patterns of direct and indirect contact between cattle and badgers naturally infected with tuberculosis. Epidemiology and Infection 2013; 141: 1467-1475.

238. Judge $\mathbf{J}$, et al. Effectiveness of biosecurity measures in preventing badger visits to farm buildings. PLOS ONE 2011; 6: e28941.

239. Roper TJ, Garnett BT, Delahay RJ. Visits to farm buildings and cattle troughs by badgers (Meles meles): a potential route for transmission of bovine tuberculosis (Mycobacterium bovis) between badgers and cattle. Cattle Practice 2003; 11: 9-12.

240. Tolhurst BA, et al. Behaviour of badgers (Meles meles) in farm buildings: opportunities for the transmission of Mycobacterium bovis to cattle? Applied Animal Behaviour Science 2009; 117: 103-113.

241. Ward AI, Judge J, Delahay RJ. Farm husbandry and badger behaviour: opportunities to manage badger to cattle transmission of Mycobacterium bovis? Preventive Veterinary Medicine 2010; 93: 2-10.

242. Roper TJ. Badger setts as a limiting resource. In: The Badger. Dublin: Royal Irish Academy, 1993, pp. 26-34.

243. Smith L A, et al. The effect of grazing management on livestock exposure to parasites via the faecal-oral route. Preventive Veterinary Medicine 2009; 91: 95-106.

244. Benham PFJ. A study of cattle and badger behaviour and farm husbandry practices relevant to the transmission of bovine tuberculosis (Mycobacterium bovis) 1985. Report to MAFF Chief Scientists' Group (1982-1985), MAFF, London.

245. Hutchings MR, Harris S. Effects of farm management practices on cattle grazing behaviour and the potential for transmission of bovine tuberculosis from badgers to cattle. Veterinary Journal 1997; 153: 149-162.

246. Gallagher J, Horwill DM. A selective oleic acid albumin agar medium for the cultivation of Mycobacterium bovis. Epidemiology \& Infection 1977; 79: 155-160.

247. Brown JA, Cheeseman CL, Harris S. Studies on the spread of bovine tuberculosis from badgers to cattle. Journal of Zoology 1992; 277: 694-696.

248. Garnett BT, Roper TJ, Delahay RJ. Use of cattle troughs by badgers (Meles meles) - a potential route for the transmission of bovine tuberculosis (Mycobacterium bovis) to cattle. Applied Animal Behaviour Science 2003; 80: $1-8$.
249. Daniels MJ, Hutchings MR, Greig A. The risk of disease transmission to livestock posed by contamination of farm stored feed by wildlife excreta. Epidemiology and Infection 2003; 130: 561-568.

250. Pavlik I. Incidence of bovine tuberculosis in wild and domestic animals other than cattle in six Central European countries during 1990-1999. Veterinarni Medicina 2002; 47.

251. Machackova M, et al. Wild boar (Sus scrofa) as a possible vector of mycobacterial infections: review of literature and critical analysis of data from Central Europe between 1983 to 2001. Veterinarni Medicina 2003; 48: 51-65.

252. Duarte EL, et al. Spoligotype diversity of Mycobacterium bovis and Mycobacterium caprae animal isolates. Veterinary Microbiology 2008; 130: 415-421.

253. Serraino A, et al. Monitoring of transmission of tuberculosis between wild boars and cattle: genotypical analysis of strains by molecular epidemiology techniques. Journal of Clinical Microbiology 1999; 37: 2766-2771.

254. Biolatti B, et al. Tuberculosis in wild boar (Sus scrofa) in Liguria (Italy). In: 34th International Symposium on Diseases of Zoo and Wild Animals, Santander, Spain, 1992, pp. 55-59.

255. Bollo E, et al. Detection of Mycobacterium tuberculosis complex in lymph nodes of wild boar (Sus scrofa) by a target-amplified test system. Journal of Veterinary Medicine, Series B 2000; 47: 337-342.

256. Kalenski P. Isolation of mycobacteria from wild boar. Veterinarstvi 1992; 42: 2.

257. Santos N, et al. Epidemiology of Mycobacterium bovis infection in wild boar (Sus scrofa) from portugaL. Journal of Wildlife Diseases 2009; 45: 1048-1061.

258. Foyle KL, Delahay RJ, Massei G. Isolation of Mycobacterium bovis from a feral wild boar (Sus scrofa) in the UK. Veterinary Record 2010; 166: 663-664.

259. Gortazar C, et al. Bovine tuberculosis in Donana Biosphere Reserve: the role of wild ungulates as disease reservoirs in the last Iberian lynx strongholds. PLoS ONE 2008: e2776.

260. Gortazar C, et al. Molecular characterization of Mycobacterium tuberculosis complex isolates from wild ungulates in south-central Spain. Veterinary Research 2005; 36: 43-52.

261. Vicente $\mathbf{J}$, et al. Wild boar and red deer display high prevalences of tuberculosis-like lesions in Spain. Veterinary Research 2006; 37: 107-119.

262. Aranaz A, et al. Bovine tuberculosis (Mycobacterium bovis) in wildlife in Spain. Journal of Clinical Microbiology 2004; 42: 2602-2608.

263. Parra A, et al. Molecular epidemiology of bovine tuberculosis in wild animals in Spain: A first approach to risk factor analysis. Veterinary Microbiology 2005; 110: 293-300.

264. Naranjo V, et al. Evidence of the role of European wild boar as a reservoir of Mycobacterium tuberculosis complex. Veterinary Microbiology 2008; 127: 1-9.

265. Gaillard J-M, Brandt S, Jullien J-M. Body weight effect on reproduction of young wild boar females: a 
comparative analysis. Folia Zoologica 1993; 42: 204 212.

266. Wilson CJ. The establishment and distribution of feral wild boar (Sus scrofa L.) in England. Wildlife Biology in Practice 2013; 10: 1-6.

267. Skuce RA, et al. Differentiation of Mycobacterium bovis isolates from animals by DNA typing. Journal of Clinical Microbiology 1996; 34: 2469-2474.

268. Aranaz A, et al. Spacer oligonucleotide typing of Mycobacterium bovis strains from cattle and other animals: a tool for studying epidemiology of tuberculosis. Journal of Clinical Microbiology 1996; 34: 2734-2740.

269. Palmer MV, Waters WR, Whipple DL. Shared feed as a means of deer-to-deer transmission of Mycobacterium bovis. Journal of Wildlife Diseases 2004; 40: 87-91.

270. Delahay RJ, et al. Bovine tuberculosis infection in wild mammals in the South-West region of England: a survey of prevalence and a semi-quantitative assessment of the relative risks to cattle. Veterinary Journal 2007; 173: 287-301.

271. Delahay RJ, et al. The status of Mycobacterium bovis infection in UK wild mammals: a review. Veterinary Journal 2001; 164: 90-105.

272. Nielsen FW, Plum N. Pulmonary tuberculosis in man as a source of infection for cattle. Veterinary Journal 1940; 96: 6-18.

273. Blacklock JWS. The epidemiology of tuberculosis. British Medical Journal 1947: 707-715.

274. Wiesmann E. Bovine tuberculosis in humans and its epidemiological significance in veterinary work [in German]. Schweizer Archiv fur Tierheilkunde 1960; 102: 467-471.

275. Werner E. Transmission of tuberculosis to a herd of cattle by an animal attendant with renal tuberculosis. Monatshefte fur Veterinarmedizin 1981; 36: 819-820.

276. Weber A, Lutz H, Bauer K. Current importance of humans for the occurrence of Mycobacterium bovis infections in herds of cattle. Berliner und Munchener Tierarztliche Wochenschrift 1988; 101: 341-344.

277. Wolter F, Schulz G, Siering W. Prevention and control of tuberculosis in cattle with reference to human medical aspects. Monatshefte fur Veterinarmedizin 1982; 37: 772-776.

278. Fritsche A, et al. Mycobacterium bovis tuberculosis: from animal to man and back. International Journal of Tuberculosis and Lung Disease 2004; 8: 903-904.

279. Fetene T, Kebede N, Alem G. Tuberculosis infection in animal and human populations in three districts of Western Gojam, Ethiopia. Zoonoses and Public Health 2011; 58: 47-53.

280. Regassa A, Medhin G, Ameni G. Bovine tuberculosis is more prevalent in cattle owned by farmers with active tuberculosis in central Ethiopia. Veterinary Journal 2008; 178: 119-125.

281. Cook AJ, et al. Human and bovine tuberculosis in the Monze District of Zambia - a cross-sectional study. British Veterinary Journal. 1996; 152: 37-46.

282. Awah-Ndukum J, et al. Preliminary report on the zoonotic significance of tuberculosis in cattle in the highlands of Cameroon. Animal hygiene and sustainable livestock production. Proceedings of the XVth International Congress of the International Society for Animal Hygiene, Vienna, Austria, 3-7 July 2011, Volume 1, 2011, pp. 193-195.

283. Brooks-Pollock E, Keeling M. Herd size and bovine tuberculosis persistence in cattle farms in Great Britain. Preventive Veterinary Medicine 2009; 92: 360-365.

284. Group IS. Badgers and cattle TB: the final report of the Independent Scientific Group on Cattle TB. Parliament Publications, 2007.

285. Woodroffe R, et al. Spatial association of Mycobacterium bovis infection in cattle and badgers Meles Meles. Journal of Applied Ecology 2005; 42: 852-862.

286. Brooks-Pollock E, Roberts GO, Keeling MJ. A dynamic model of bovine tuberculosis spread and control in Great Britain. Nature 2014; 511: 228.

287. Guta S, et al. Epidemiological investigation of bovine tuberculosis herd breakdowns in Spain 2009/2011. PLOS ONE 2014; 9.

288. Woodbine KA, et al. Seroprevalence and epidemiological characteristics of Mycobacterium avium subsp. paratuberculosis on 114 cattle farms in south west England. Preventive Veterinary Medicine 2009; 89: 102-109.

289. Claridge $\mathbf{J}$, et al. Fasciola hepatica is associated with the failure to detect bovine tuberculosis in dairy cattle. Nature Communications 2012; 3: 853.

290. McCann CM, Baylis M, Williams DJ. Seroprevalence and spatial distribution of Fasciola hepatica-infected dairy herds in England and Wales. Veterinary Record 2010; 166: 612-617.

291. Bishop SC, Woolliams JA. Genomics and disease resistance studies in livestock. Livestock Science 2014; 166: $190-198$.

292. Anon. Genetic index to help breed dairy cows with greater resistance to bovine TB. Veterinary Record 2016; 178: 56.

293. Leach M, Scoones I. The social and political lives of zoonotic disease models: Narratives, science and policy. Social Science \& Medicine 2013; 88: 10-17.

294. Catley A, Alders RG, Wood JLN. Participatory epidemiology: approaches, methods, experiences. Veterinary Journal 2012; 191: 151-160.

295. Broughan JM, et al. Farm characteristics and farmer perceptions associated with bovine tuberculosis incidents in areas of emerging endemic spread. Preventive Veterinary Medicine. Accepted. 129: 88-96.

296. Cox DR, et al. Simple model for tuberculosis in cattle and badgers. Proceedings of the National Academy of Sciences USA 2005; 102: 17588-17593.

297. Richardson IW, et al. Variance components for susceptibility to Mycobacterium bovis infection in dairy and beef cattle. Genetics, Selection, Evolution 2014; 46: 77.

298. Alvarez J, et al. Bovine tuberculosis: within-herd transmission models to support and direct the decisionmaking process. Research in Veterinary Science. 2014; 97 (Suppl.): S61-S68.

299. Jin R, et al. Association between rainfall and bovine $\mathrm{TB}$ in Wicklow, Ireland. Veterinary Record 2013; 173: 452 . 
300. Maddock ECG. Further studies on the survival time of the bovine tubercle bacillus in soil, soil and dung, in dung and on grass, with experiments On feeding guinea-pigs and calves on grass artificially infected with bovine tubercle bacilli. Journal of Hygiene 1934; 34: 372-379.

301. Maddock ECG. Studies on the survival time of the bovine tubercle bacillus in soil, soil and dung, in dung and on grass, with experiments on the preliminary treatment of infected organic matter and the cultivation of the organism. Journal of Hygiene 1933; 33: 103-117.

302. King E, Lovell D, Harris S. Effect of climate on the survival of Mycobacterium bovis and its transmission to cattle herds in south-west Britain. Advances in Vertebrate Pest Management, 1999, pp. 14-161. 